\title{
Quantitatively determine the dominant driving factors of the spatial-temporal changes of vegetation-impacts of global change and human activity
}

shijun wang

State Grid Corporation of China

ping chang

State Grid Corporation of China

ning wang ( 1450822397@qq.com )

China Aerospace Corporation Organization: China Aerospace Science and Technology Corporation jin wen

China Aerospace Science and Technology Corporation

ke zhang

State Grid Corporation of China

kun yuan

State Grid Corporation of China

jun yang

State Grid Zhejiang Electric Power Co Electric Power Research Institute

\section{Research Article}

Keywords: Vegetation NDVI, Climate change, Gravity center, Spatial-temporal evolution, Geodetector

Posted Date: February 25th, 2022

DOI: https://doi.org/10.21203/rs.3.rs-1259626/v1

License: (c) (i) This work is licensed under a Creative Commons Attribution 4.0 International License. Read Full License 


\title{
1 Quantitatively determine the dominant driving factors of the
} spatial-temporal changes of vegetation-impacts of global change

\section{and human activity}

\author{
ShiJun Wang ${ }^{1}$,Chang Ping ${ }^{1}$, Ning Wang, ${ }^{2,}$, Jing Wen $^{2}$, Ke Zhang ${ }^{3}$, Kun Yuan ${ }^{3}$,Jun \\ Yang $^{4}$ \\ ${ }^{1}$ Economy \& Technology Research Institute, Gansu Electric Power Corporation, State Grid, \\ Lanzhou 730050, China \\ ${ }^{2}$ China Aero Geophysical Survey and Remote Sensing Center for Natural Resources, Beijing \\ 100101, China; \\ ${ }^{3}$ Anhui Nanrui Jiyuan Electricity Grid Technical Co.Ltd., Hefei 230088,China. \\ ${ }^{4}$ State Grid Hangzhou Power Supply Company, HangZhou 310000, China. \\ *Corresponding Author E-mail: 1461521281@qq.com
}

Abstract: The differences of spatial-temporal distribution patterns and dominant driving factors of vegetation evolution in different regions and different historical periods were not clearly. Therefore, this study introduced the gravity center model and geodetector to analyze the spatial-temporal change characteristics and dominant driving factors of vegetation NDVI in China during 1981-2019 from the perspective of geographic divisions. Results showed that: (1) During 1981-2019, the average vegetation coverage in China, as a whole, showed an increasing trend and zones with obviously increasing vegetation NDVI were mainly distributed in the middle reaches of the Yellow River basin and the upper reaches of the Yangtze River. (2) During 1981-2019, the gravity centers of vegetation NDVI, nationally, were mainly concentrated in Yan'an City and Tongchuan City, showing a southward migration trend as a whole, which indicates that the increment and growth rates of the southern were greater than those of the northern part. (3) The growth of vegetation in southern China was primarily affected by temperature, while that of northern China was largely influenced by precipitation. (4) Specific factors, including land use, precipitation and 
soil types exerted significant influences on the vegetation NDVI, and their interaction could enhance the influence of single factor.

Key words: Vegetation NDVI; Climate change; Gravity center; Spatial-temporal evolution; Geodetector

\section{Introduction}

As an important part of terrestrial ecosystem, vegetation plays an important role in the material cycle, energy flow and information transmission for the terrestrial ecosystem (Josep et al. 2009; Guo et al., 2020a; Gomes et al. 2021; Wu et al.,2021). Vegetation is not only the natural link between soils, the atmosphere and water, but also the component most sensitive to climate change (Hu and Guo 2012; Guo et al.,2020b;Lu et al.,2020). Under the stress of global climate change, the spatialtemporal evolution pattern of vegetation is the result of climate change, land use, soil and water conservation and other natural activities, as well as human activities (Li and Shi 2000; Wu et al. 2015; Shi et al. 2018; Guo et al., 2020c). Previous studies have shown that climate change led to a significant increase in vegetation biomass in the northern hemisphere, and the same trend of vegetation change has also been detected in China (Fang et al. 2003; Liu et al. 2015; Guo et al., 2020d). Vegetation changes will trigger the fluctuation of the whole terrestrial ecosystem to a certain extent. Quantitative analysis of spatial-temporal change patterns of vegetation change and exploring its driving factors are of great significance for the improvement of ecological environment.

Vegetation index that monitored by satellite remote sensing and other quantitative indicators have been adopted to analyze the hydrological response of vegetation at different scales, which has provided a convenient approach to reveal the characteristics of regional terrestrial ecological environment. As an important indicator of vegetation growth, the normalized difference vegetation index (NDVI) can accurately reflect the growth rate and state of surface vegetation, which has been widely applied in the investigation of spatial-temporal changes of vegetation (Liu et 
al. 2012; Ya et al. 2015; Zheng et al. 2016; Jin 2019;Guo and Wen, 2020). Zhong et al. (2010) analyzed the spatial-temporal pattern of vegetation NDVI on the Qinghai-Tibet Plateau based on SPOT-VGT NDVI from 1998 to 2006, and found that the spatial distribution of vegetation NDVI was consistent with the climatic pattern of the Qinghai-Tibet Plateau. Wu et al. (2014) investigated the changes of global vegetation coverage over the past 30 years, and found that the annual variation of global average vegetation coverage fluctuated between an index of 0.2 and 0.6 , and most of the global continental vegetation showed an increasing trend (except for Oceania). Piao et al. (2011) analyzed the changes in vegetation coverage in the cool temperate zone of Eurasia from 1982 to 2006 based on GIMMS NDVI data, and found that the change of vegetation NDVI in Eurasia had obvious stages. Chen et al. (2021) analyzed the influencing factors of vegetation in different climatic regions of the Yellow River Basin from 1982 to 2015, indicating that precipitation exerted the greatest impacts on vegetation NDVI in semi-arid areas, whereas temperature had the greatest impacts on vegetation NDVI in semi-humid areas. By exploring the response of global vegetation NDVI to extreme weather events, Liu et al. (2013) found that vegetation in semihumid and semi-arid areas, especially temperate grasslands and hardwood forests, were very sensitive to extreme precipitation events. Lu et al. (2020) utilized the datasets of GIMMS NDVI of the vegetation growing season from 1982 to 2012 to investigate the spatial-temporal response characteristics of NDVI, temperature and precipitation of the 8 typical vegetation coverage types in China. Zhang et al. (2020) analyzed the characteristics of vegetation change in Inner Mongolia based on SPOT NDVI data from 2000 to 2015, and found that annual precipitation, soil type, vegetation type and annual average temperature played a dominant role in the spatialtemporal change process of vegetation NDVI. The above previous studies showed the average NDVI of growing season was significantly correlated with the average temperature and precipitation with obviously great differences. In addition, the human activities had played more important role in the evolution process of surface 
vegetation rather than natural factors. However, the differences of dominant factors in different sub-region in China during different periods were urgent to clarify, which was urgent and critical for regional protection of vegetation ecosystem (Liu et al.,2013; Jin et al.,2020). Moreover, how to distinguish the effects of natural factors and human activities was still a difficult problem and a hot issue in the field of ecology（Gao et al.,2019; Lu et al.,2020; Chen et al.,2021）.

Therefore, based on the datasets of GIMMS NDVI, MODIS NDVI and meteorological data, this paper introduced the gravity center model and geodetector to analyze the spatial-temporal evolution patterns of vegetation NDVI in China from 1981 to 2019 and then quantitatively determined the dominant factors in different subregions during different periods.

\section{Materials and methods}

Study area

China is located in eastern Asia, the west coast of the Pacific Ocean, bordering North Korea on the east, and facing South Korea and Japan across the sea, Kyrgyzstan, Tajikistan, Pakistan and India in the west, Vietnam, Laos and Myanmar to the south, and Russia and Mongolia in the north (Figure 1). China covers a vast territory, spanning nearly 50 degrees latitude from north to south and more than 60 degrees longitude from east to west, with the area of about 9.6 million $\mathrm{km}^{2}$. The eastern part of China has a monsoon climate, while the northwest region and Qinghaiare dominated by temperate continental climate and alpine climate, respectively. The topography of China is complex and diverse, including plateaus (19\%), mountains (26\%), hills $(10 \%)$, plains $(12 \%)$ and basins (19\%). The distribution characteristics of vegetation types in China are greatly affected by climatic factors, which can be categorized into eight types: cold temperate coniferous forest, temperate coniferous and deciduous broad-leaved mixed forest, warm temperate deciduous broad-leaved forest, subtropical evergreen broad-leaved forest, tropical monsoon rain forest, temperate steppe, temperate desert and alpine vegetation on the Qinghai-Xizang 
Plateau.

113

114

115

116

117

118

119

120

121

122

123

124

125

126

127

128

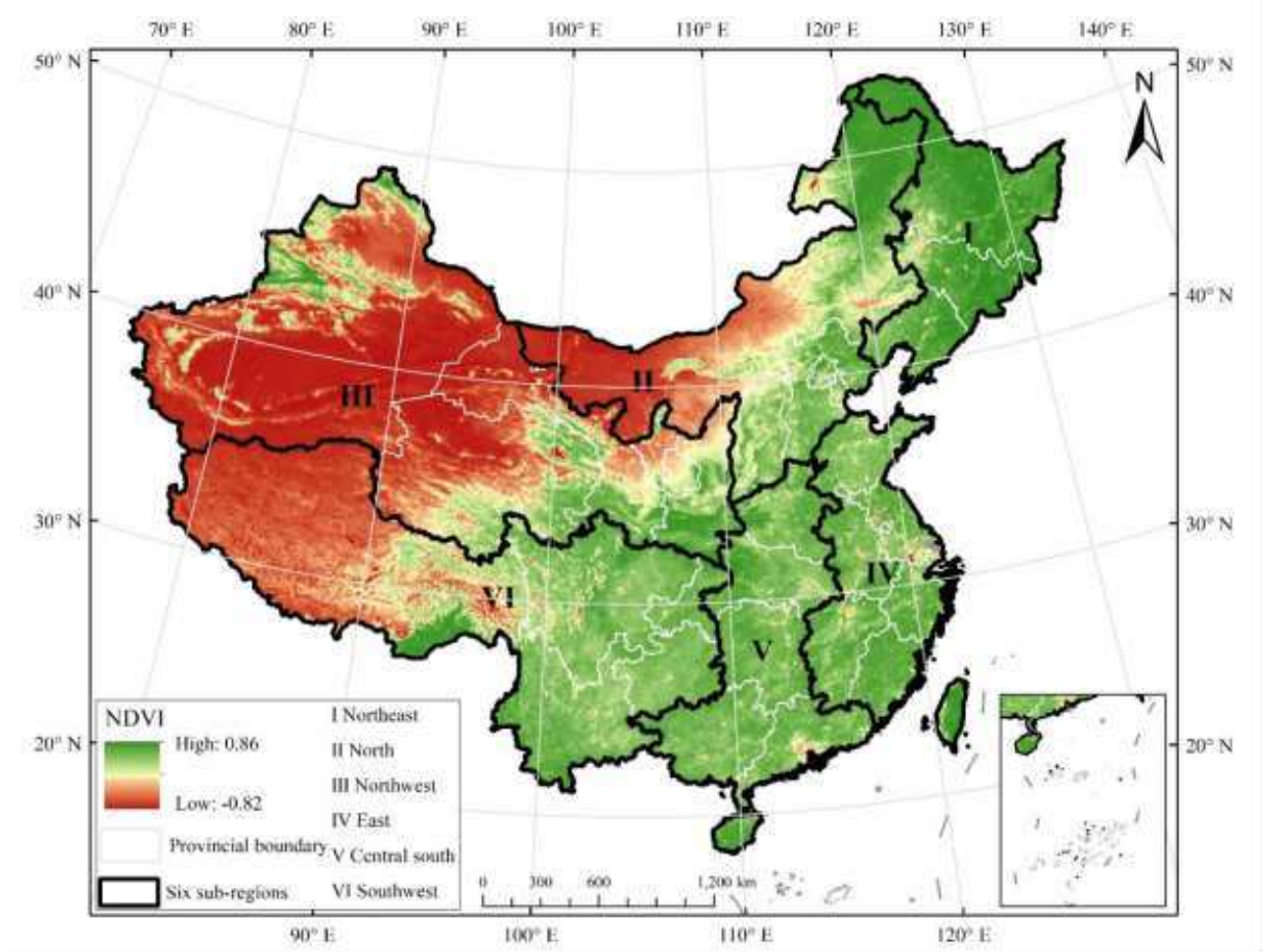

Figure 1. Geographical location of China

\section{Data sources and pre-processing}

The meteorological data was obtained from the China Meteorological Data Network (http://data.cma.cn/), including daily precipitation $(0.1 \mathrm{~mm})$, daily average temperature $\left(0.1^{\circ} \mathrm{C}\right)$, sunshine hour $(0.1 \mathrm{~h})$ and other factors from 824 ground meteorological stations in China. Then the grid datasets, including temperature, precipitation, sunshine and accumulated temperature, with a spatial resolution of $8 \mathrm{~km}$ were obtained by the interpolation with the method of Kriging method of ArcGIS 10.2 and C\#. The Normalized Difference Vegetation Index (NDVI) data include GIMMS NDVI (1981-2006a, at a 15d temporal resolution and $8 \mathrm{~km}$ spatial resolution) and MODIS NDVI data (2000-2019a, at a 16d temporal resolution and $1 \mathrm{~km}$ spatial resolution) were downloaded from the Resource and Environment Data Cloud Platform (https://www.resdc.cn/) and Geospatial Data Cloud (http://www. gscloud.cn/). In order to confirm the consistency of the spatial resolution, the MODIS NDVI datasets were resampled into images with $8 \mathrm{~km}$ and the annual NDVI were 
129 obtained utilizing the maximum value calculation method. Considering the different

130 sources of the two datasets, this study constructed the correction model by regression

131 analysis based on the overlapping year's data from 2000 to 2006: YMODISNDVI $=$

$1321.0777 \mathrm{X}_{\text {GIMMSNDVI }}+0.0046\left(\mathrm{R}^{2}=0.925, \mathrm{P}<0.001\right)$. Then, the above model was

133 utilized to correct the MODIS NDVI from 2007 to 2019. The land use data of 1980

134 and 2020 with the spatial resolution of $1 \mathrm{~km}$ was obtained from the Resource and

135 Environment Data Cloud Platform (https://www.resdc.cn/), which is used to analyze

136 the influences of anthropogenic interference on vegetation. Digital Elevation Model

137 (DEM) data that derived from STRM3 was collected from Geospatial Data Cloud

138 with a spatial resolution of $90 \mathrm{~m}$. All these above datasets with different spatial

139 resolution were interpolated to grids with the spatial resolution of $8 \mathrm{~km}$ utilizing the

140 tool of Resample of ArcGIS 10.2.

141 Methods

142 The workflow of this study was showed in Figure 2.

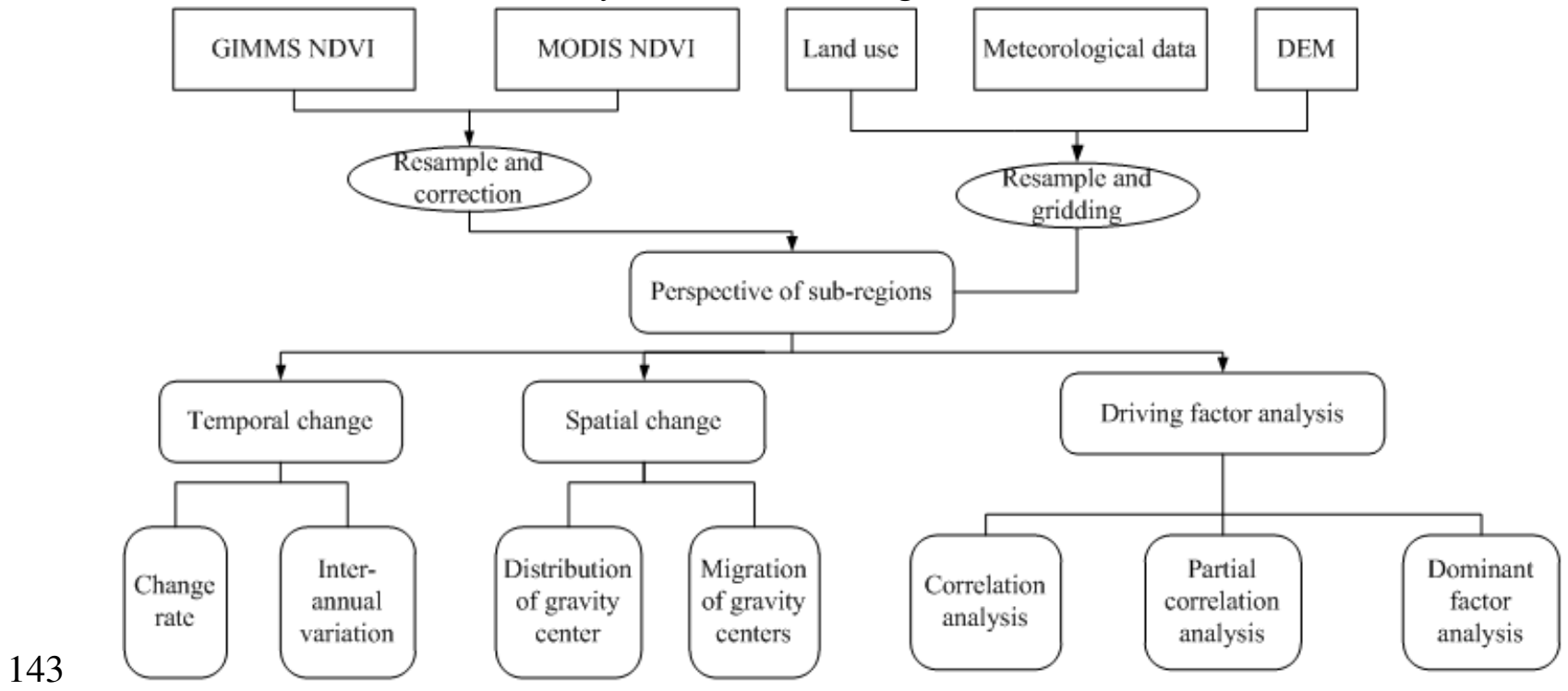

144

Figure 2. The workflow of the study

145 Linear trend and change rate

146 Linear trend is to utilize a univariate linear regression to analyze the change

147 intensity and trend of regional vegetation. The calculation formula is as follows

148 (Zhang et al. 2015; Li et al. 2018; Sun et al. 2019): 


$$
\text { slope }=\frac{n \times \sum_{i=1}^{n}\left(i \times M_{N D V I, i}\right)-\sum_{i=1}^{n} i \sum_{i=1}^{n} M_{N D V I, i}}{n \times \sum_{i=1}^{n} i^{2}-\left(\sum_{i=1}^{n} i\right)^{2}}
$$

149

150

151 year $(i)$. If slope $>0$, it indicates that the vegetation condition has been improved;

152 otherwise, it means that the vegetation condition has degraded.

153 The change rate of vegetation was used to indicate the change degree of 154 vegetation NDVI in study periods, and its equation is as follows:

164 (excluding the influence of other elements), and multiple correlation analysis reflects 165 the comprehensive influence of each factor. The corresponding calculations formulas 166 are as follows (Yang et al. 2019; Chen et al. 2020; Peng et al. 2020):

$$
\begin{aligned}
& r_{x, y}=\frac{\sum_{k=1}^{n}\left(x_{k}-\bar{x}\right)\left(y_{k}-\bar{y}\right)}{\sqrt{\sum_{k=1}^{n}\left(x_{k}-\bar{x}\right)^{2} \sum_{k=1}^{n}\left(y_{k}-\bar{y}\right)^{2}}} \\
& r_{\mathrm{xy}_{1}, \mathrm{y}_{2}}=\frac{\mathrm{r}_{\mathrm{xy}}-\mathrm{r}_{\mathrm{xy}_{2}} \mathrm{r}_{\mathrm{y}_{1} \mathrm{y}_{2}}}{\sqrt{1-\mathrm{r}_{\mathrm{xy}}^{2}} \sqrt{1-\mathrm{r}_{\mathrm{y}_{1} \mathrm{y}_{2}}^{2}}} \\
& \mathrm{R}_{\mathrm{x}, \mathrm{y}_{1} \mathrm{y}_{2}}=\sqrt{1-\left(1-\mathrm{r}_{\mathrm{xy}_{1}}^{2}\right)\left(1-\mathrm{r}_{\mathrm{xy}_{2}, \mathrm{y}_{1}}^{2}\right)}
\end{aligned}
$$


Where $r_{x, y}$ represents the correlation coefficient between the independent variable

168 and the dependent variable (in this article, the relationship between NDVI and climate

169 elements), $\bar{x}, \bar{y}$ refer to the average value of the two variables and $x_{k}, y_{k}$ denote the

170 value of the year $(k)$ of the two variables. $\mathrm{r}_{\mathrm{xy}_{1}, \mathrm{y}_{2}}$ means the partial correlation value

171 between $x$ and $y_{1}$ after fixed $y_{2}$, and $\mathrm{r}_{\mathrm{xy}_{2}, \mathrm{y}_{1}}$ represents the similar meaning of $\mathrm{r}_{\mathrm{xy}_{1}, \mathrm{y}_{2}} \cdot r_{x y_{1}}$

172 refers to the correlation coefficient between $x$ and $y_{1}$ and $\mathrm{r}_{\mathrm{xy}_{2}}, \mathrm{r}_{\mathrm{y}_{1} \mathrm{y}_{2}}$ represents similar

173 meaning as $r_{x y_{1}} \cdot \mathrm{R}_{\mathrm{x}, \mathrm{y}_{1} y_{2}}$ refers to the multiple correlation coefficient between $\mathrm{x}$ and $y_{1}$,

$174 y_{2}$. Considering the confidence levels of $\mathrm{p}<0.05$ and $\mathrm{p}<0.01$, the significant

175 relationships between NDVI and temperature, precipitation have been discussed. T

176 test (Eqs.(5)) is adopted to analyze the significance of the partial correlation

177 coefficient, and the F-test (Formula (6)) is utilized to analyze the significance of the

178 multiple correlation coefficient.

$$
\begin{aligned}
& \mathrm{T}=\frac{\mathrm{r}_{\mathrm{xy}}, \mathrm{y}_{2}}{\sqrt{1-\mathrm{r}_{\mathrm{xy}_{1}, \mathrm{y}_{2}}}} \sqrt{\mathrm{n}-\mathrm{m}-1} \\
& \mathrm{~F}=\frac{\mathrm{R}_{\mathrm{x}, \mathrm{y}_{1} \mathrm{y}_{2}}^{2}}{1-\mathrm{R}_{\mathrm{x}, \mathrm{y}_{1} \mathrm{y}_{2}}^{2}} \times \frac{\mathrm{n}-\mathrm{k}-1}{\mathrm{k}}
\end{aligned}
$$

179 Gravity centre model and standard deviation ellipse

180 Gravity center can better reflect the unbalance of spatial-temporal distribution of 181 geographical elements, which has been widely utilized in economy, population 182 studies, ecology and other fields. In addition, the migration trajectory of the gravity 183 centre of vegetation NDVI can also directly indicate the imbalance of grown rate and 184 increments in different parts through the map form. The gravity center of a region is 185 defined as: if a region is composed of $n$ sub-regions, where the coordinate of gravity 186 center of the sub-region $i$ is $\left(\mathrm{x}_{\mathrm{i}}, \mathrm{y}_{\mathrm{i}}\right), M_{i}$ stands for the attribute value of the sub187 region, then the geographical coordinate of gravity center of the region is expressed as 188 (Rong and Fang 2017; Guo et al. 2019): 


$$
\begin{aligned}
& \bar{x}=\frac{\sum_{i=1}^{n} M_{i} x_{i}}{\sum_{i=1}^{n} M_{i}} \\
& \bar{y}=\frac{\sum_{i=1}^{n} M_{i} y_{i}}{\sum_{i=1}^{n} M_{i}}
\end{aligned}
$$

189

190

191

192

193

194

195

196

197

198

199

200

201

202

203

The standard deviation ellipse is mainly composed of the rotation angle, the standard deviation along the principal axis (major axis) and the auxiliary axis (minor axis). The long axis represents the direction of the largest spatial distribution of gravity centre, while the short axis denotes the direction of the least spatial distribution of gravity centers (Zhu et al. 2019). The standard deviation ellipse can be applied to identify the change and migration trend of vegetation NDVI gravity centers in the region, because it can more directly reflect the spatial evolution trend of vegetation coverage.

\section{Geodetector}

The geodetector model is utilized to detect the spatial differentiation of vegetation NDVI in order to reveal the explanatory power of a factor to NDVI (Li et al. 2016; Peng et al. 2019). The correlation degree is measured by the q value, which is ranged $[0,1]$. The higher the value, the more obvious the explanatory power of the influencing factor $(\mathrm{X})$ to vegetation $\operatorname{NDVI}(\mathrm{Y})$, and vice versa, which can be expressed as follows:

$$
\begin{gathered}
q=1-\frac{\sum_{h=1}^{L} N_{h} \sigma_{h}^{2}}{N \sigma^{2}}=1-\frac{S S W}{S S T} \\
S S W=\sum_{h=1}^{L} N_{h} \sigma_{h}^{2} \\
S S T=N \sigma^{2}
\end{gathered}
$$

where $h=1, \ldots ., L$ stands for the classifications of variable $\mathrm{Y}$ or $\mathrm{X} ; N_{h}$ denotes 205 the number of units of class $h$, and $N$ represents the number of units of the whole 
region. $\sigma_{\mathrm{h}}^{2}$ refers to the variance of $Y$ value of class $h$ and $\sigma^{2}$ means the variance of

207 Y value of the whole region. SSW refers to the sum of the variance in layer, and SST 208 represents the total variance of the whole region.

209 Results

210 Change rate of vegetation NDVI in China during 1981-2019

211 Based on the analysis of the change rate of vegetation NDVI in China from 1981

212 to 2019 (Figure 3), the study indicated that in the past 40 years, zones of change rate 213 between $-10 \%$ and $10 \%$ that belonged to stable areas had largest area with accounting 214 for $35.57 \%$. Zones of change rate between $10 \%$ and $30 \%$ that belonged to slightly 215 increased areas accounted for $23.42 \%$. Zones of change rate less than $-30 \%$ that 216 belonged to significantly reduced areas had the smallest area, accounting for $2176.93 \%$.The above analysis results showed that the average vegetation coverage in 218 China has shown an overall increasing trend in the past 40 years with the stable areas $219(-10 \% \sim 10 \%)$ and increased areas $(>10 \%)$ amounting to $78.22 \%$ of the total study area.

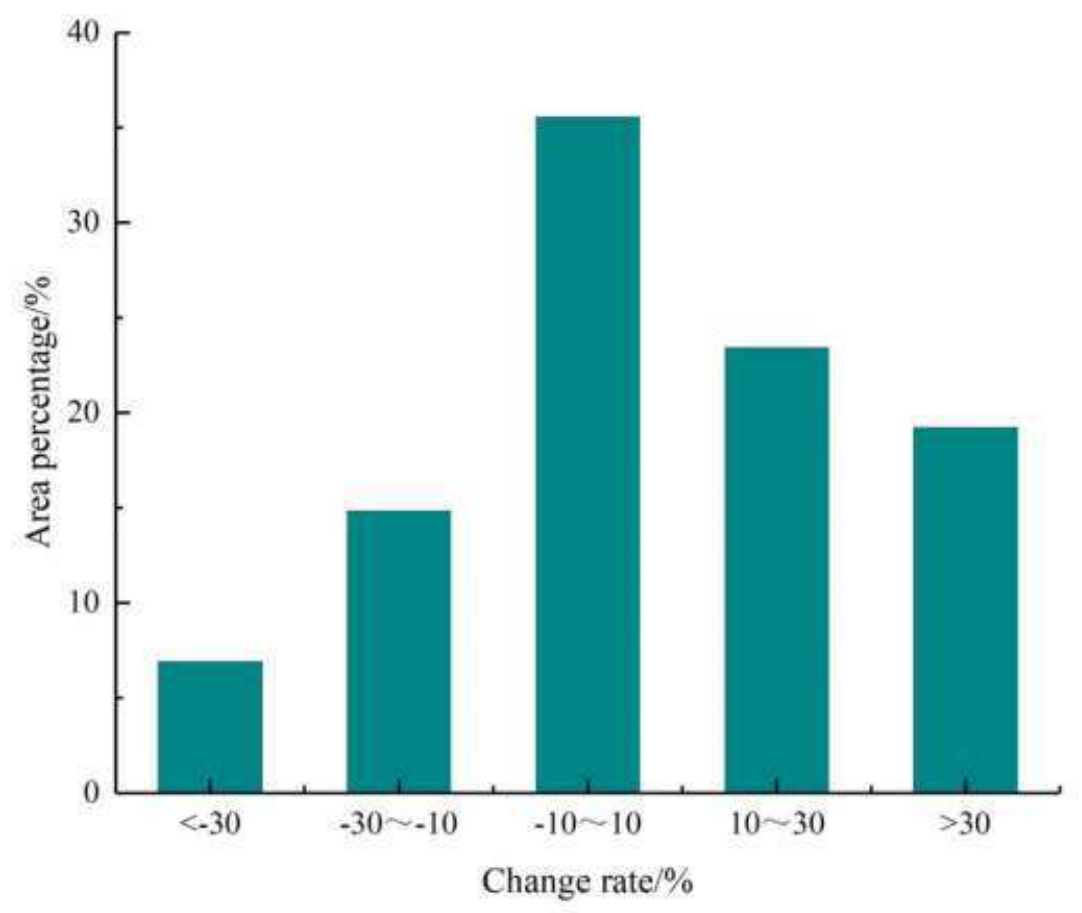

Figure 3. Area percentage of different grades of NDVI change rate in China in recent 40 years

As is shown in Figure 4, zones of the change rate between $-10 \%$ and $10 \%$ were 
224 the most widely distributed, mainly concentrated in southern Xinjiang, western Inner

225 Mongolia and the northern Qinghai-Tibet Plateau. Zones of NDVI change rate more 226 than $30 \%$ were mainly distributed in the middle and upper reaches of the Yellow 227 River, the middle and upper reaches of the Yangtze River and the Liaohe River basin. 228 The slightly reduction zones of NDVI $(-30 \%<$ change rate $<-10 \%)$ were mainly 229 distributed in northern China, including northern Heilongjiang, northeastern Inner 230 Mongolia and so on.

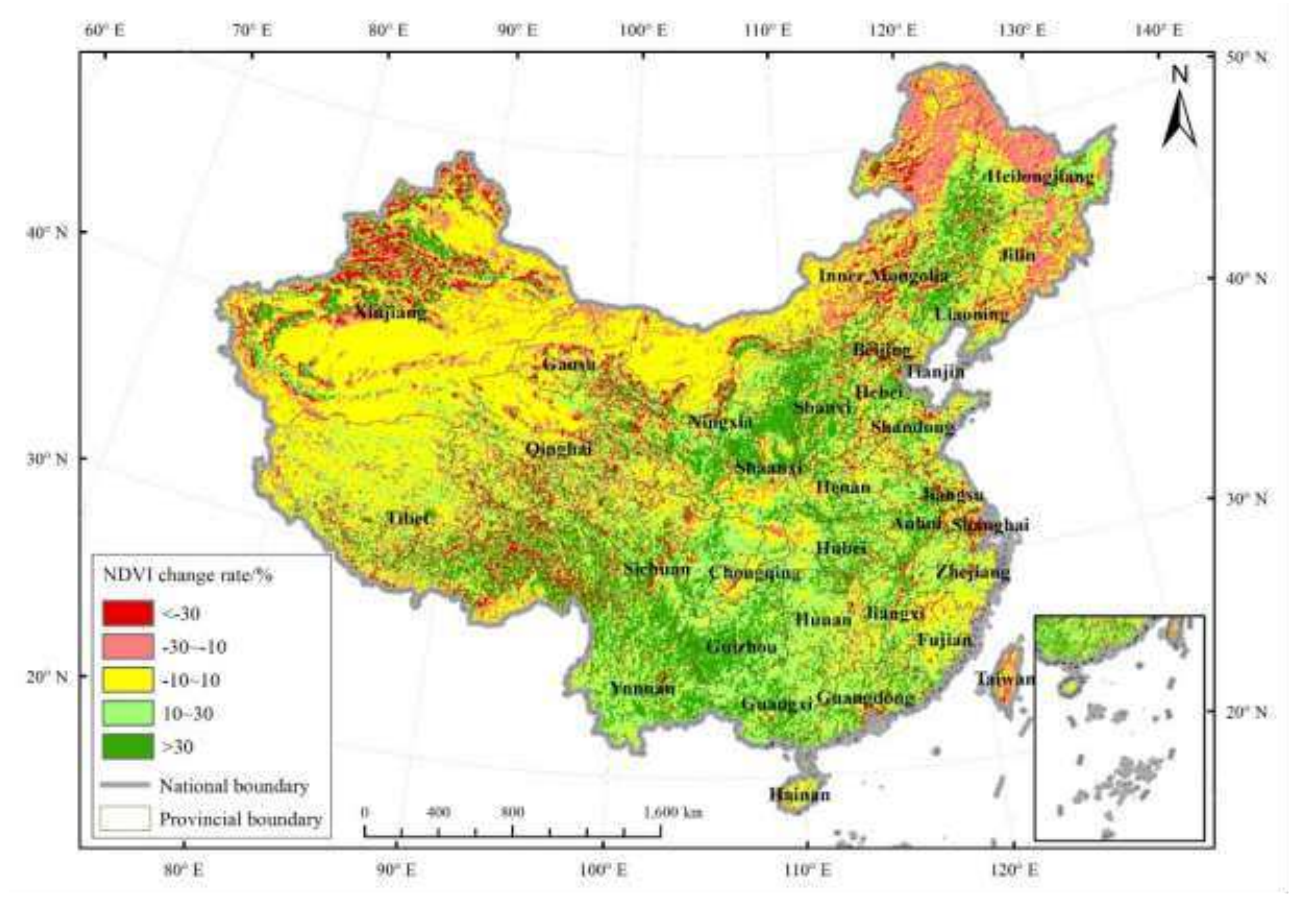

Figure 4. Spatial distribution of different grades of NDVI change rate in China in recent 40 years

\section{Inter-annual variation of vegetation coverage in China}

235 From the inter-annual variations of vegetation NDVI (Figure 5), the overall 236 fluctuation range of vegetation NDVI in China was relatively large in the past 40 237 years. Among them, the annual average vegetation NDVI in northeast China was the 238 largest, which amounted to 0.830 , followed by that of the central-south part $(0.752)$.

239 The northwest part, a desert and grassland-dominated area whose vegetation growth 240 was restricted by precipitation, had the minimum annual NDVI, which only reached 241 0.294. During the study period, the minimum of NDVIs in most areas appeared 242 around 2000, which may be a consequence of meteorological disasters. Since 1999, 
243 the projects of "returning farmland to forest and grassland" and afforestation have

244 been implemented in various regions of China with remarkable result, the average

245 NDVI of national scale and different sub-regions showed a fluctuating increasing

246 trend. The results were consistent with results of Zhao et al (2018) and Jin et al

247 (2020). Before 2000, the NDVIs in most areas of China decreased in varying degrees,

248 among which the northeast region was the most serious, and its NDVI value

249 decreased from 0.834 in 1981 to 0.757 in 2000 , with a decrease rate of $0.077 / 20$ a.

250 After 2000, the NDVI in China has increased in varying degrees, basically consistent

251 with the previous research results.
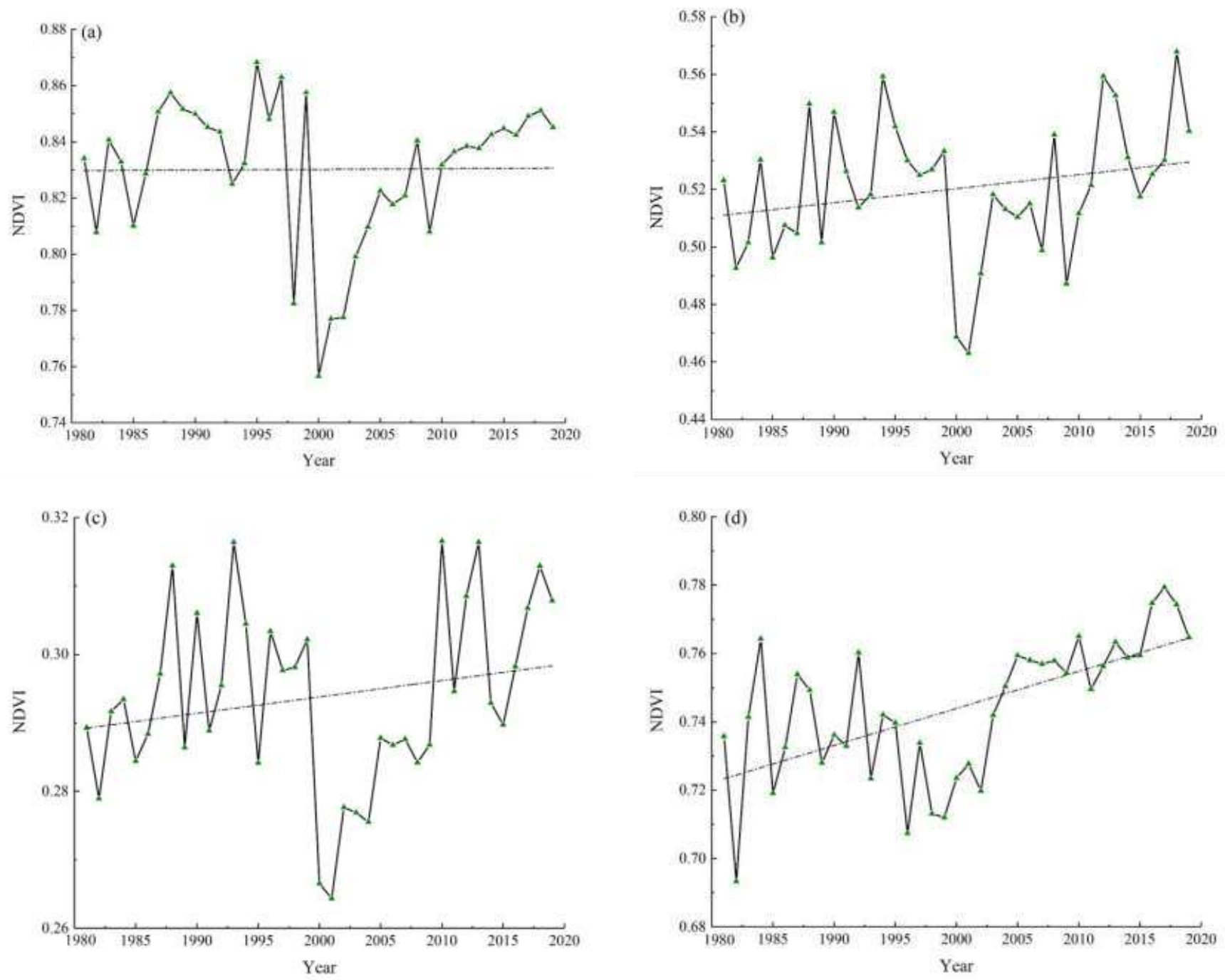

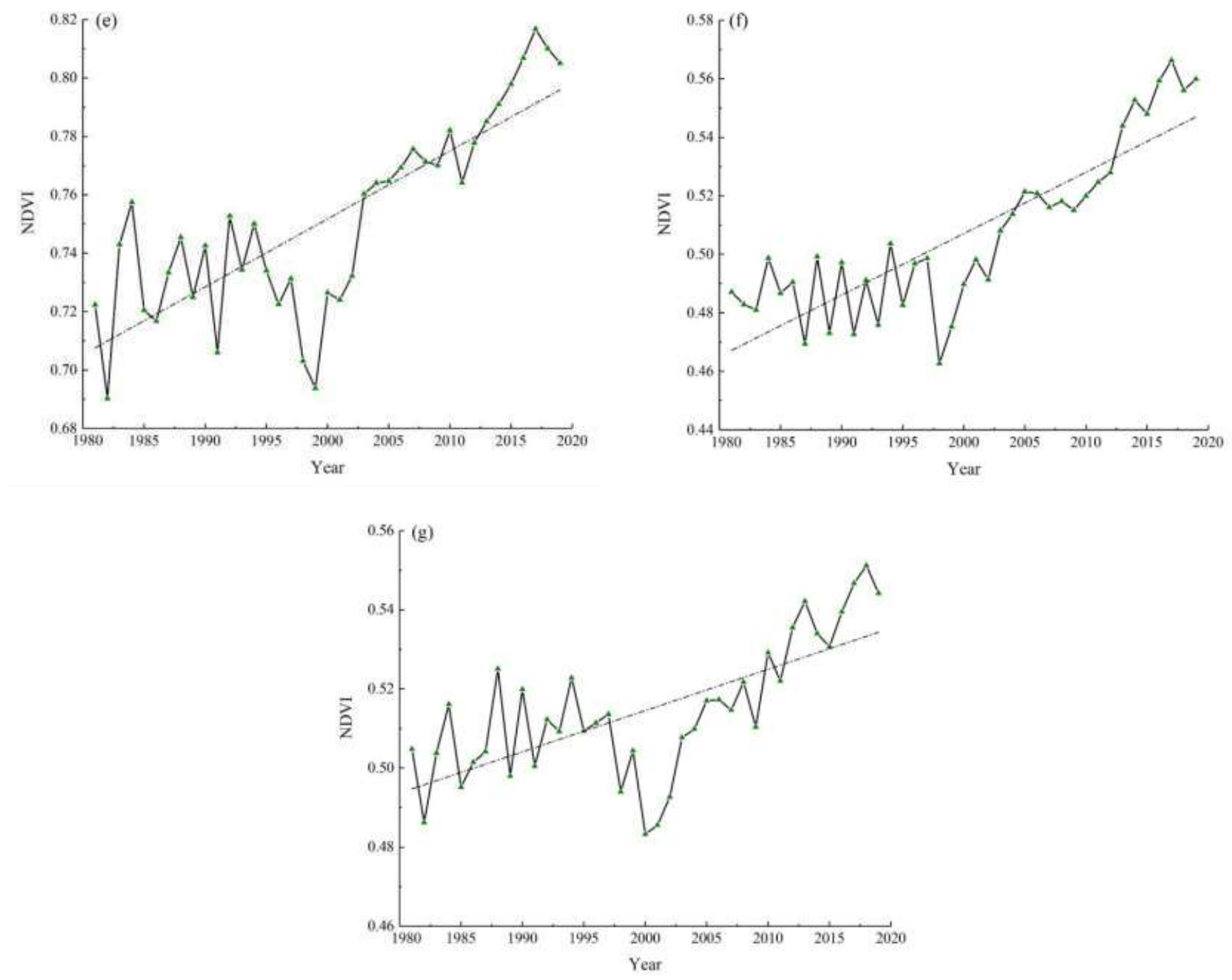

252 Figure 5. Change trend of annual mean values of NDVIs at the national scale and in different geographical regions (a) northeast ; (b)north ; (c)northwest ; (d)east ; (e)central south ;

(f)southwest ; (g)national

\section{Migration trajectory of gravity centers}

256 Distributions of gravity center of vegetation coverage at national and 257 regional scale

258 In order to explore the imbalance and bias of the spatial distribution of 259 vegetation NDVI in the study area, the gravity center model was utilized to analyze 260 the dynamic changes of national and regional NDVI in recent 40 years. As was shown 261 in Figure 6, the standard deviation ellipse was adopted to identify the change and 262 migration trend of gravity centers. Utilizing a polar coordinate system and taking the 
average gravity center of the NDVI from 1981 to 2019 as the origin, the distance (polar radius) and offset angle (polar angle) to the origin were calculated to directly reflect the migration direction and distance of the gravity center.

The gravity centers of vegetation NDVI in northeast China were mainly concentrated in Harbin, Heilongjiang Province. The area of the standard deviation ellipse was $92.62 \mathrm{~km}^{2}$ (Table 1), which was the smallest among the six sub-regions, indicating that the distribution of NDVI gravity centers was relatively concentrated. In the polar coordinate system, the proportion of the gravity centers in the north half (northeast quadrant and northwest quadrant) was $84.62 \%$, whereas the proportion of the gravity centers in the south half (southwest quadrant and southeast quadrant) was merely $15.38 \%$, which was much smaller than that in the north half, demonstrating that the grown rate and increment of the vegetation NDVI in the south half was smaller than that in the north half. The gravity centers of NDVI in north China were mainly distributed in Xilingol League and Chifeng City, Inner Mongolia. The area of standard deviation ellipse in north China was significantly larger than that of northeast China, which showed that the change of vegetation NDVI in north China was more salient than that in northeast China. The gravity centers of vegetation NDVI in northwest China were mainly concentrated in the vicinity of the polar angle of the line from $150^{\circ}$ to $330^{\circ}$, which showed a northwest-southeast distribution pattern as a whole. The shape of the standard deviation ellipse was flatter, which had the largest area of $1549.87 \mathrm{~km}^{2}$ in the six sub-regions, showing that the spatial distribution of the gravity centers was obviously uneven.

The distribution of gravity centers of vegetation NDVI in east China was concentrated mainly in Huangshan City, Anhui Province. The rotation angle of standard deviation ellipse was $90.75^{\circ}$, and the gravity centers were distributed in north-south direction. During 1981-2019, the gravity centers of vegetation NDVI were distributed in the northern half, accounting for $64.10 \%$, while the gravity centers of vegetation NDVI in the southern half accounted for $35.90 \%$, indicating that the 
291 increment and growth rate of vegetation NDVI in the northern parts was higher than 292 that in the southern parts. The gravity centers of NDVI in the central south were 293 mainly distributed in Zhaoyang City, Hunan Province, and the angle of standard 294 deviation ellipse was $71.50^{\circ}$, suggesting that the gravity centers were distributed from 295 northeast to southwest as a whole. The NDVI gravity centers in southwest China were 296 distributed in the northwest-southeast direction, the standard deviation ellipse major 297 axis was in the northwest-southeast direction, with a length of $20.21 \mathrm{~km}$, and the 298 minor axis was in the northeast-southwest direction, with a length of $5.35 \mathrm{~km}$, 299 demonstrating that the discreteness of the NDVI gravity center in the northwest300 southeast direction was greater than that in the northeast-southwest direction. From 301 the polar coordinate images, it could be found that there were two years when the 302 deviation distance of NDVI gravity centers was larger, which were 1981 and 1988, 303 respectively, indicating that the increment of NDVI gravity center in the northwest 304 was more significant in these two years.

305 The national NDVI gravity centers were mainly distributed in Yan'an City and 306 Tongchuan City, Shaanxi Province, the standard deviation ellipse area was 1450.26 $307 \mathrm{~km}^{2}$, and spatial distribution of the gravity centers was relatively discrete. The 308 distribution of the gravity centers in the four quadrants under the polar coordinate 309 system was relatively uniform, in which the gravity centers in the northeast quadrant 310 were the largest, reaching $28.20 \%$, followed by the northwest quadrant $(25.64 \%)$, 311 whilst the southwest quadrant and the southeast quadrant had the same proportion, 312 both standing at $23.08 \%$. The proportion of the gravity centers in the north half $313(53.84 \%)$ was greater than that in the south half $(46.16 \%)$, indicating that the 314 increment of the NDVI gravity center in the northern half was higher than that in the 315 southern half. Prior to 2000, the gravity center of NDVI was mostly concentrated in 316 the northern part, and after 2000, the gravity center was mostly concentrated in the 317 southern part, indicating that the gravity center had a trend of southward movement. 318 Among them, there were four years with a deviation distance within $10 \mathrm{~km}$, namely 
3192002 , 2005, 2011 and 2012, and only in one year (1999) an offset distance ranged

320 between $40 \sim 50 \mathrm{~km}$ occurred, indicating that the increment of vegetation NDVI in the

321 north was larger in that year.

322 Table 1. Standard deviation ellipse parameters of NDVIs in China and different sub-regions from 1981 to 2019

\begin{tabular}{|ccccccccc|}
\hline $\begin{array}{c}\text { Standard deviation } \\
\text { ellipse parameters }\end{array}$ & Northeast & North & Northwest & East & Central South Southwest & National \\
\hline Rotation angle $\left({ }^{\circ}\right)$ & 104.86 & 74.80 & 151.03 & 90.75 & 71.50 & 157.62 & 92.61 \\
& Major axis $(\mathrm{km})$ & 7.30 & 23.89 & 54.79 & 10.91 & 10.36 & 20.21 & 28.93 \\
324 & Minor axis $(\mathrm{km})$ & 4.04 & 10.94 & 9.01 & 3.55 & 4.53 & 5.35 & 15.96 \\
& Area $\left(\mathrm{km}^{2}\right)$ & 92.62 & 820.92 & 1549.87 & 121.73 & 147.59 & 339.37 & 1450.26 \\
\hline
\end{tabular}
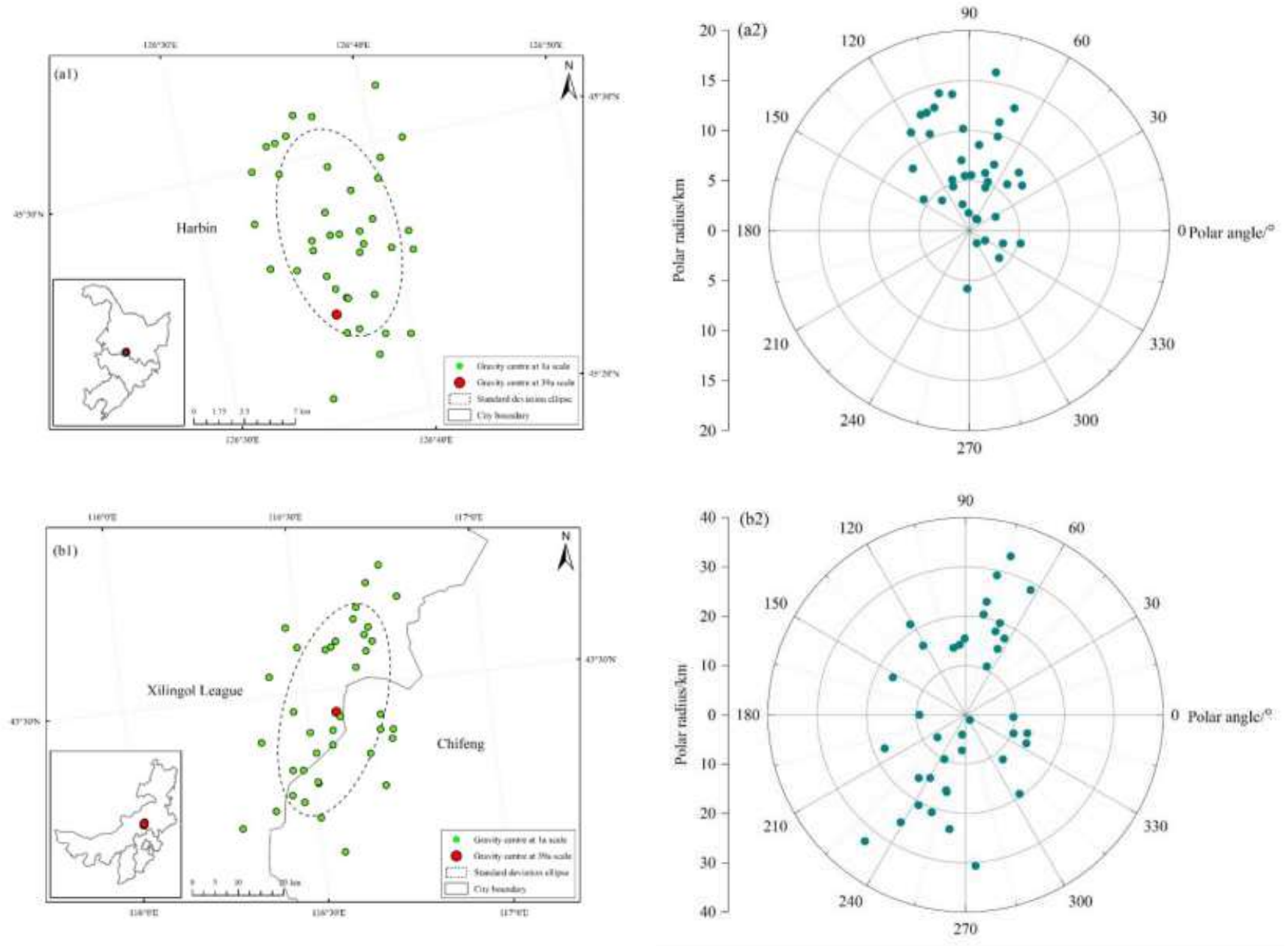

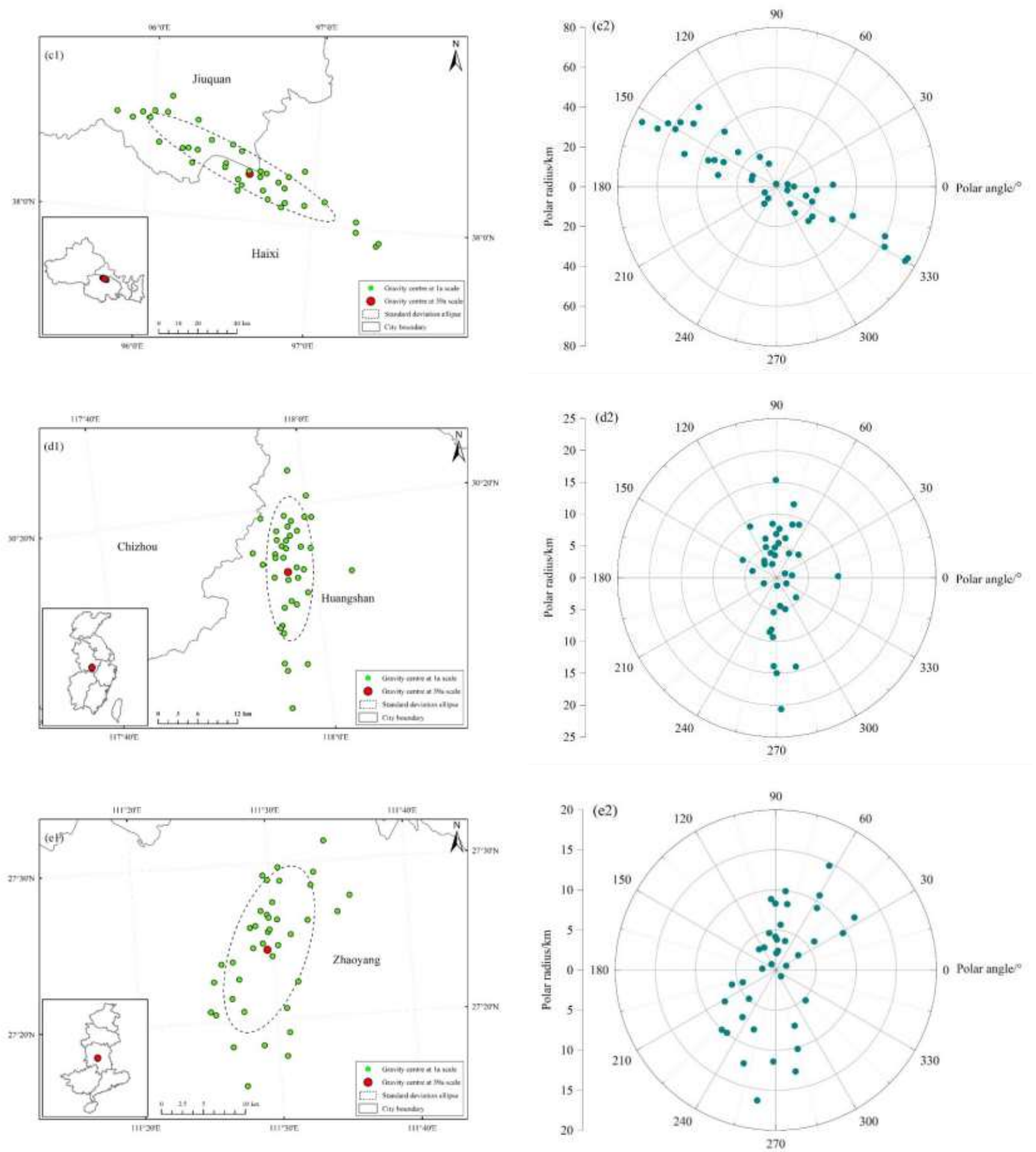

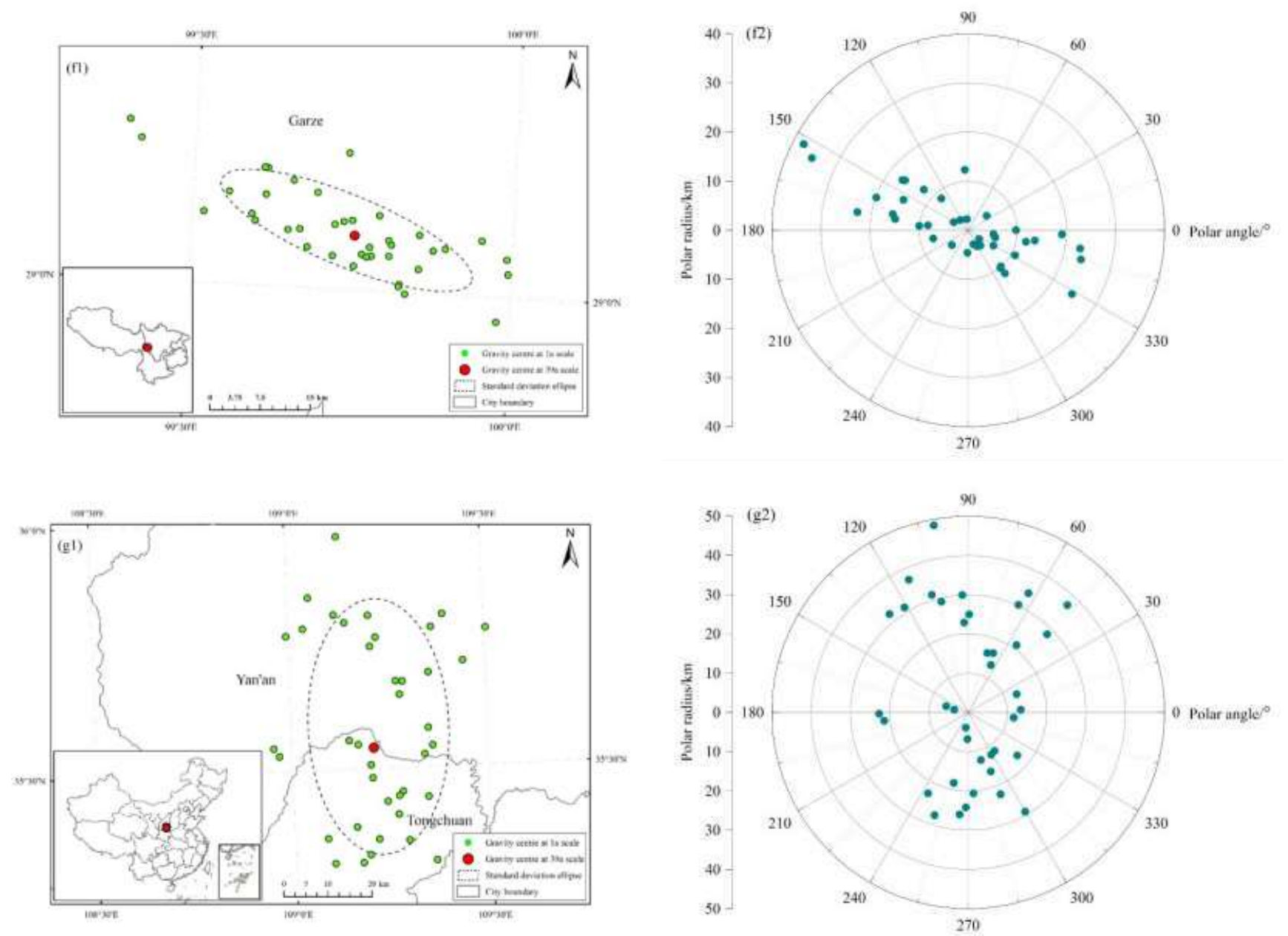

325 Figure 6. Distribution of gravity centers of NDVI at the national scale and in different sub-regions

326 (a1) northeast (in space) ; (a2) northeast (in polar coordinates) ; (b1) north (in space) ; (b2) north

327 (in polar coordinates) ; (c1) northwest (in space) ; (c2) northwest (in polar coordinates) ; (d1)

328 east (in space) ; (d2) east (in polar coordinates) ; (e1) central south (in space) ; (e2) central south

329 (in polar coordinates) ; (f1) southwest (in space) ; (f2) southwest (in polar coordinates) ; (g1) national (in space); (g2) national (in polar coordinates)

\section{Migration of gravity centers of vegetation NDVI at national and regional}

332 scales

333 In order to further analyze the spatial variation of vegetation NDVI in the study 334 area, the gravity center migration of vegetation NDVI on the basis of a 5-year scale 335 from 1981 to 2019. As was shown in Figure 7, during 1981-2000, the gravity centers 336 of vegetation NDVI in northeast China showed a migration trend of southwest- 
northeast-southwest. The gravity center of 2006-2010 migrated to the southwest, compared with that of 2001-2005, indicating that the growth rate and increments of vegetation NDVI in the southwest was larger than that in the northeast during this

340 period. However, compared with gravity centers of 2011-2015 and 2016-2019, those 341 of 2006-2010 showed a northward swinging trend. On the whole, in the past 40 years, 342 the gravity center of vegetation NDVI in northeast China showed a moving trend of 343 south-north, and the distance to the south was greater than that to the north. The 344 gravity center of vegetation NDVI in north China exhibited obvious regularity. The 345 gravity center of 2006-2015 shifted northward, and in other periods, the gravity 346 centers gradually shifted to the south, suggesting that the increment of the gravity 347 center in the south was larger than that in the north. Among them, the migration 348 distance of the gravity center of 1996-2000 to 2001-2005 was the largest, which 349 amounted to $15.07 \mathrm{~km}$, while that of 1991-1995 to 1996-2000 was the smallest with $350 \quad 2.04 \mathrm{~km}$. The gravity centers of NDVI in northwest China migrated northwestward in 351 the first three periods, namely $1981-1985$ to $1986-1990,1986-1990$ to $1991-1995$, and 352 1991-1995 to 1996-2000, respectively. In the last four periods, they all moved to the 353 southeast, namely, $1996-2000$ to $2001-2005$, 2001-2005 to 2006-2010, 2006-2010 to 354 2011-2015, and 2011-2015 to 2016-2019. Among them, the migration distance from $3551996-2000$ to $2001-2005$ was the maximum with $50.53 \mathrm{~km}$. From 2001-2005 to 20063562010 , the migration distance was the minimum with $4.73 \mathrm{~km}$.

357 The gravity center of vegetation NDVI in east China from 1986 to 1990 shifted 358 to the northwest compared with that from 1981 to 1985 . During the five periods from 3591986 to 2015 , the migration trajectory of the gravity centers of NDVI exhibited a 360 circular trend of "southwest to northeast to northeast to southwest to south", whereas 361 the gravity center continued to migrate southward from 2016 to 2019 compared with 362 that from 2011 to 2015 . The migration trajectory of the gravity center of NDVI in 363 central south China showed a "Z" shape. The gravity center of 1981-1985 to 19863641990 migrated northeastward, while that of 1986-1990 to $1991-1995,2006-2010$ to 
2011-2015 and 2011-2015 to 2016-2019 moved to the southwest. Meanwhile, the gravity centers migrated to the northwest in the three periods of 1991-1995 to1996$2000,1996-2000$ to $2001-2005$ and $2001-2005$ to $2006-2010$. The gravity center of vegetation NDVI in the central south China showed a trend of moving to the southwest as a whole. The gravity centers of NDVI in southwest China in 1986-1990 and 1991-1995 shifted to the northwest compared with that in 1981-1985 and the migration distance of 1981-1985 to 1986-1990 was the largest. The gravity centers of 1991-1995 to 1996-2000 and 2001-2005 to 2006-2010 both shifted to the southeast, while the gravity center of 1996-2000 migrated to the southwest compared to that of 2001-2005. And gravity centers of 2011-2015 and 2016-2019 moved northwest compared with that of 2006-2010.

The gravity centers of national vegetation NDVI were mainly concentrated in Yan'an City, Shaanxi Province in the first four periods (1981-2000), and Tongchuan

378 City in the last four periods (2001-2019). The gravity center of vegetation NDVI 379 shifted to the northwest during 1986-1990 compared with that of 1981-1985, 380 indicating that the increment and growth rate of vegetation NDVI in the northwest of 381 the study area was larger than that in the southeast during this period. The gravity 382 centers of vegetation NDVI in the two periods of 1991-1995 and 1996-2000 moved to 383 the southwest as a whole compared with that of 1986-1990, indicating that the 384 increment of vegetation NDVI in southwest China was larger than that in northeast 385 China in recent decade. The gravity center of 1996-2000 migrated to the southeast 386 compared to that of 2001-2005 and its migration distance was the maximum. The 387 gravity center of 2006-2010 migrated westward compared with 2001-2005. From 3882006 to 2019 , the gravity center first moved to the northwest and then to the 389 southwest. Base on the analysis, in the past 40 years, the gravity center of vegetation 390 NDVI shifted to the south as a whole, and the migration distance amounted to 36.25 $391 \mathrm{~km}$. 

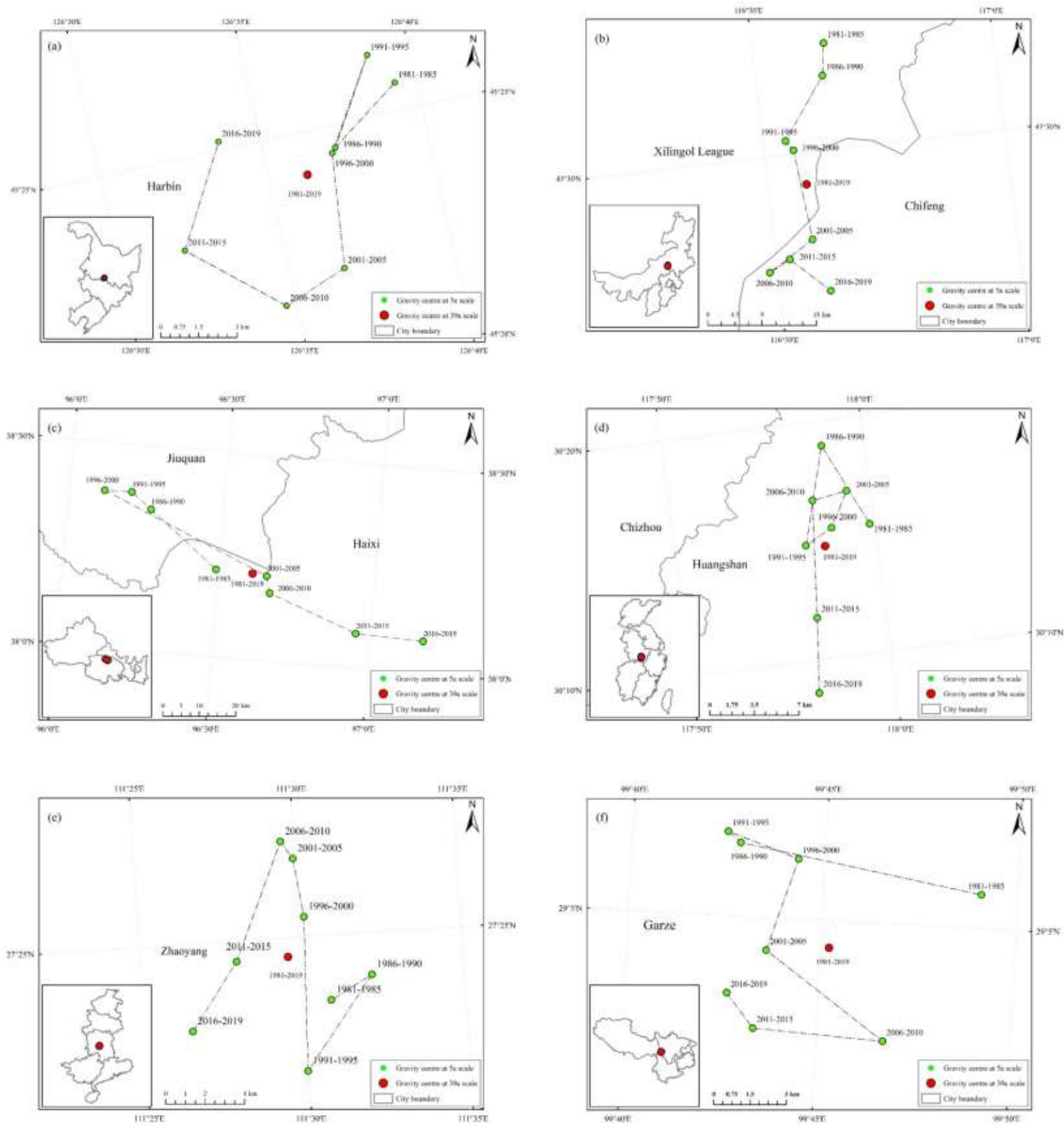


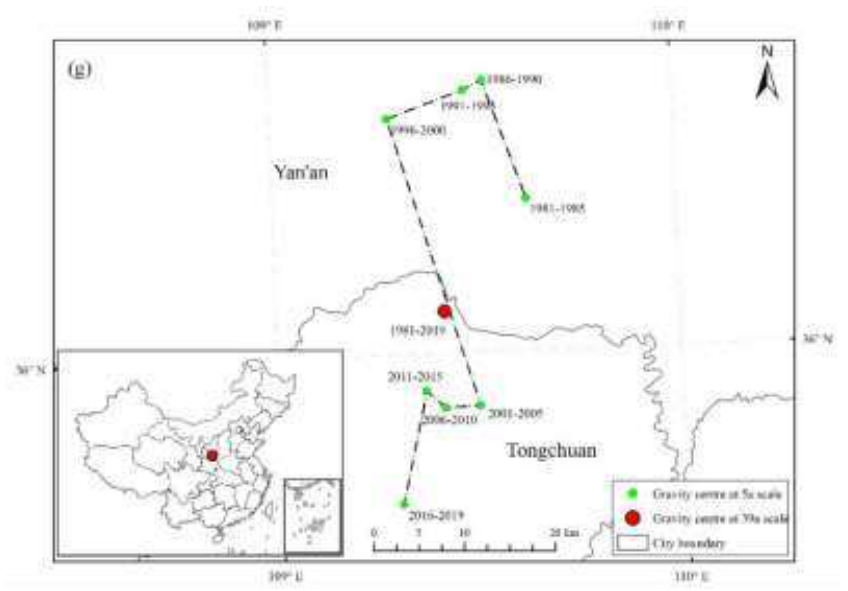

392

393

Figure 7. Migration trajectory of gravity centers of NDVI at the national scale and in different subregions (a) northeast ; (b) north ; (c) northwest ; (d) east ; (e) central south ;

(f) southwest ; (g)national

\section{Influence of single climate factor on vegetation NDVI}

The vegetation grown was significantly influenced by climate factors. In this study, we analyzed the correlation between vegetation NDVI and single climate factor, and the correlation coefficients between NDVI and temperature, precipitation, sunshine and accumulated temperature were calculated based on pixel scale.

As was shown in Figure 8(a), zones with significantly positive correlation $(\mathrm{P}<0.01)$ between NDVI and temperature accounted for $53 \%$ of the total area, which were mainly distributed in the south parts that around latitude $35^{\circ} \mathrm{N}$. Zones with negative correlation $(\mathrm{P}<0.05)$ between NDVI and temperature were mainly concentrated in the northern part of China (near latitude $40^{\circ} \mathrm{N}$ ), including central Xinjiang, the Inner Mongolia-Gansu border zone, northwest of Gansu and Qinghai, the Inner Mongolia Plateau and the central Northeast Plain. As was shown in Figure $8(\mathrm{~b})$, zones with positive correlation $(\mathrm{P}<0.05)$ between NDVI and precipitation accounted for $60 \%$ of the total area, which were mainly distributed in the Inner Mongolia Plateau and the middle and upper reaches of the Yellow River basin. Zones with negative correlation $(\mathrm{P}<0.05)$ between NDVI and precipitation were mainly concentrated in the Tarim Basin, the Qaidam Basin in Xinjiang and the western part of 
412 Inner Mongolia Plateau. In southern China, in areas such as Yunnan, Hubei, Anhui,

413 Jiangsu, the correlation between NDVI and precipitation was also negative. Figure

$4148(\mathrm{c})$ showed that $42 \%$ of the total area exhibited a positive correlation $(\mathrm{P}<0.05)$

415 between NDVI and sunshine, and zones with obvious positive correlation mainly

416 concentrated in central Xinjiang, Gansu and northwest Qinghai, and the western

417 Yunnan-Guizhou Plateau. Zones with negative correlation $(\mathrm{P}<0.05)$ between NDVI

418 and sunshine were mainly concentrated in central China (between $105^{\circ} \mathrm{E}$ and $115^{\circ} \mathrm{E}$ ),

419 such as Guizhou, Shanxi and Henan. Figure 8(d) showed that zones with negative

420 correlation $(\mathrm{P}<0.05)$ between NDVI and accumulated temperature accounted for $50 \%$

421 of the total area, which were mainly concentrated in northern China, including the

422 three provinces in northeast China, Inner Mongolia an Xinjiang.
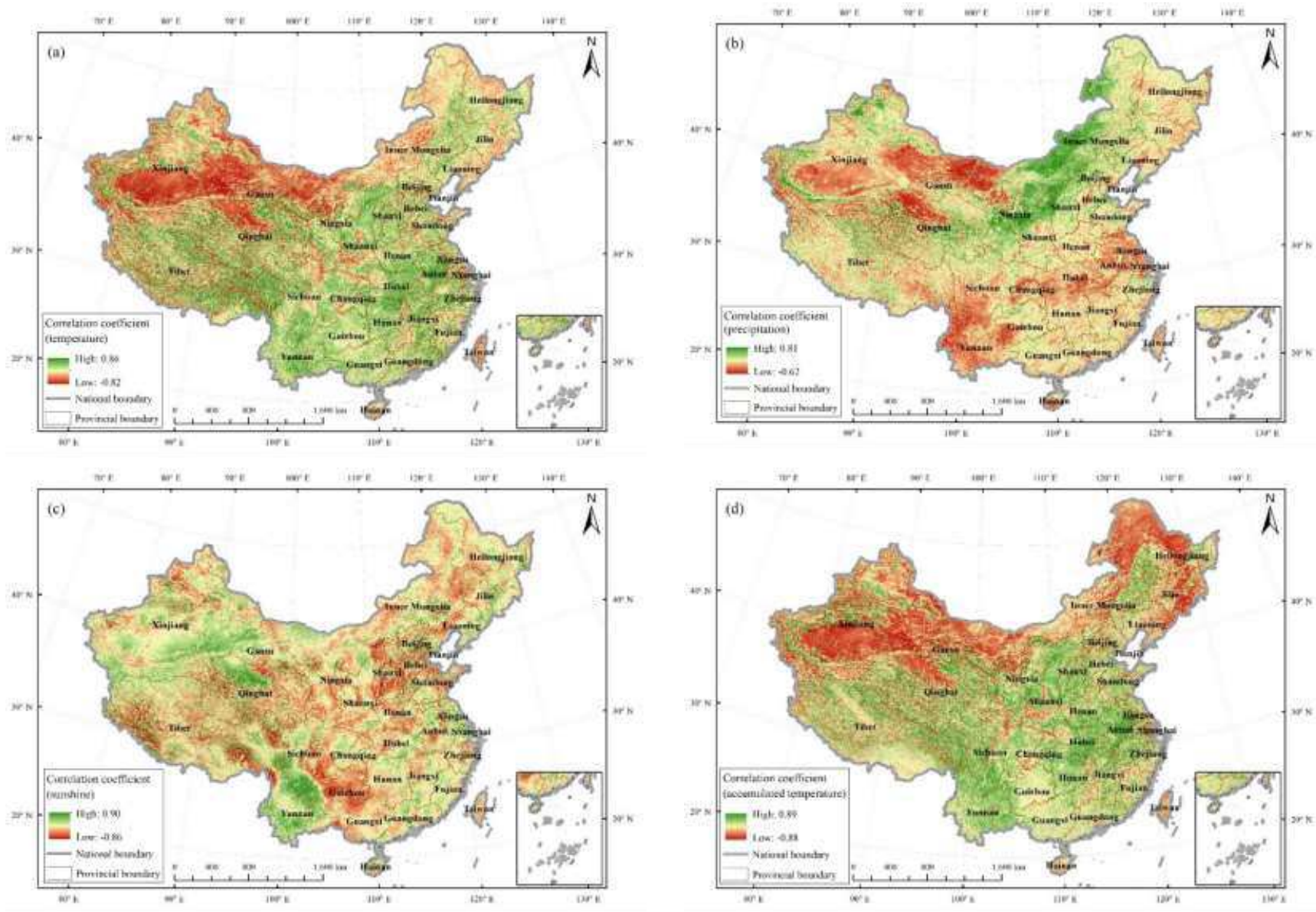

423 Figure 8. Correlation analysis of vegetation NDVI and climatic factors (a) NDVI and temperature;

424 (b) NDVI and precipitation; (c) NDVI and sunshine; (d) NDVI and accumulated temperature

$425\left(>10^{\circ} \mathrm{C}\right)$ 


\section{Influence of double climate factors on vegetation NDVI}

Partial correlation analysis could eliminate the influence of other elements, while multiple correlation analysis could reflect the comprehensive influence of each factor. Because the vegetation NDVI was affected by a variety of climatic factors and the climatic factors in this study were often interactive and independent. Considering that temperature and precipitation were the main factors affecting change of vegetation NDVI, this study calculated the partial correlation coefficients and multiple correlation coefficients between vegetation and temperature, precipitations in China from 1981 to 2019 and tested its level of significance.

As was shown in Figure 9(a), the partial correlation between NDVI and temperature ranged from -0.82 to 0.87 . Zones with positive correlation were mainly concentrated in east China, south-central and southwest China, accounting for $53.65 \%$ of the total area, while zones with negative correlation were mainly distributed in the central area of Xinjiang, Inner Mongolia, Qinghai and Gansu, and the eastern area of the Northeast Plain, amounting to $46.35 \%$ of the total area. As was shown in Figure $8(\mathrm{c})$, zones with positive correlation between NDVI and precipitation were mainly distributed in north China and the border area of Shaanxi-Ningxia-Gansu, accounting for $60.34 \%$ of the total area. Meanwhile, the areas with negative correlation were mainly distributed in central Xinjiang, western Inner Mongolia and most areas in the south, amounting to $39.66 \%$ of the total area. As was shown in Figure 9(b) and Figure 9(d), the zones with extremely significant positive correlation between NDVI and temperature accounted for $18.32 \%(\mathrm{P}<0.01, \mathrm{R}>0)$, which were mainly concentrated in the Qinghai-Tibet Plateau, Loess Plateau and southeastern coastal areas. Zones with significant positive correlation $(\mathrm{P}<0.05, \mathrm{R}>0)$ accounted for $8.43 \%$, while the area proportion of extremely significant negative correlation $(\mathrm{P}<0.01, \mathrm{R}<0)$ was $15.33 \%$, mainly concentrated in northern arid and semi-arid areas, such as central Xinjiang and western Inner Mongolia. Zones with significant negative correlation $(\mathrm{P}<0.05, \mathrm{R}<0)$ accounted for only $5.92 \%$. The partial correlation between vegetation NDVI and 
precipitation did not pass the significance test in most areas, and only $17.72 \%$ of the

455 areas passed the significance level test. Zones with extremely significant positive correlation accounted for $8.19 \%$, which were mainly distributed in the Inner Mongolia Plateau and the border area of Shaanxi-Ningxia-Gansu .Zones with significant positive correlation $(\mathrm{P}<0.05)$ accounted for only $6.25 \%$, while zones with extremely significant negative correlation $(\mathrm{P}<0.01)$ covered the smallest area, accounted for only $0.81 \%$. Meanwhile, zones with significant negative correlation area accounted for $2.48 \%$.

As was shown in Figure 9(e), the multiple correlation coefficient between NDVI temperature and precipitation ranged from 0 to 0.88 , and the areas with larger multiple correlation coefficients mainly concentrated in central and southern Xinjiang, northern Inner Mongolia, Gansu-Ningxia-Shaanxi border zone, southern Tibet, northern Qinghai and the middle part of the middle and lower reaches of the Yangtze River, whilst the areas with smaller multiple correlation coefficients mainly distributed in the Northeast Plain and southeast coastal areas. Figure 9(f) was the result of $\mathrm{F}$ significance test, in which $14.98 \%$ of the pixels in the multiple correlation test represented significant regions $(\mathrm{P}<0.05)$ and $35.55 \%$ referred to extremely significant regions $(\mathrm{P}<0.01)$, which mainly distributed in the northern arid and semi-

72 arid regions, the Qinghai-Tibet Plateau, the northern Loess Plateau and the middle and

the
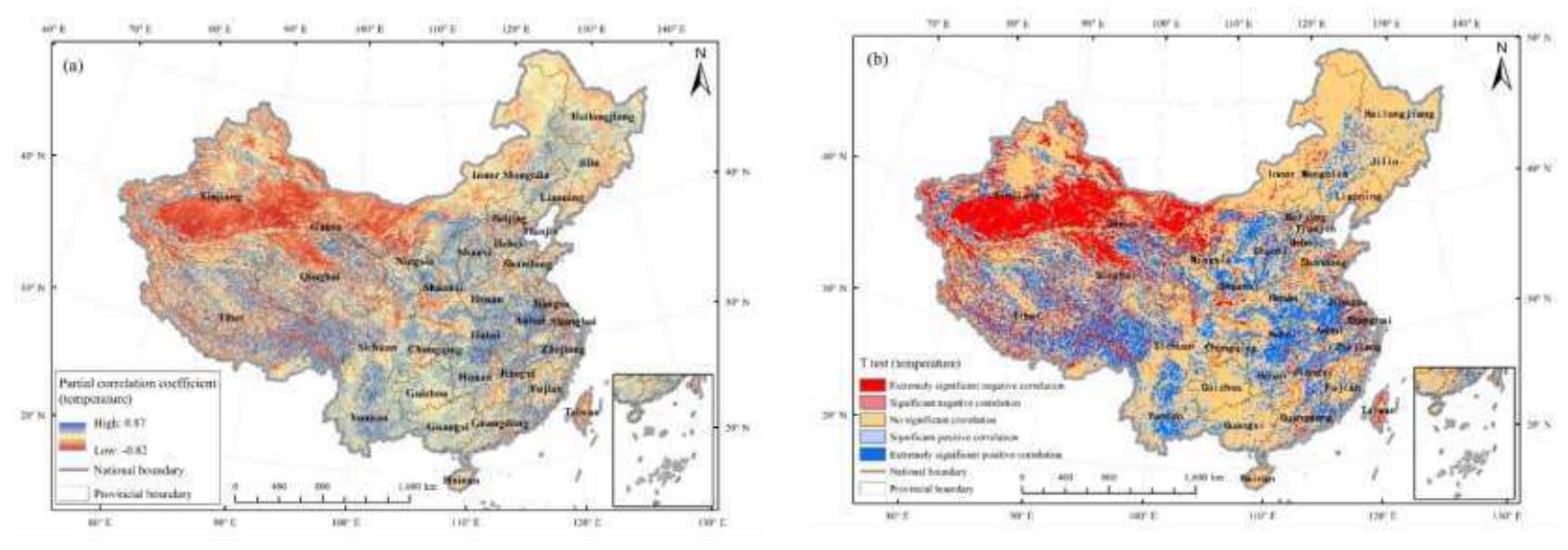

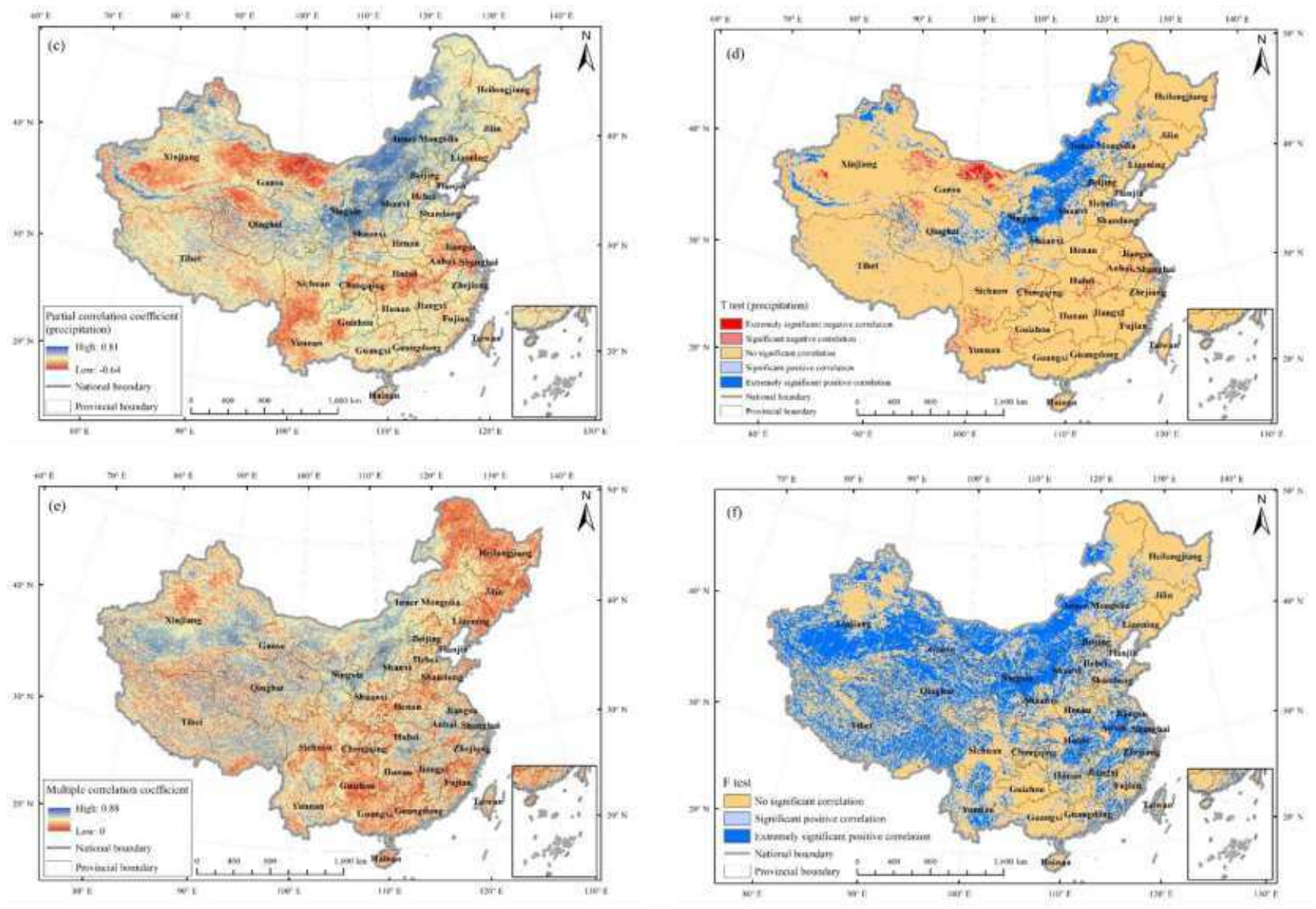

474 Figure 9. Partial correlation coefficient, multiple correlation coefficient and significance tests on

475 vegetation NDVI and temperature, precipitation (a) temperature partial correlation coefficient; (b)

476 T significance test (temperature); (c) precipitation partial correlation coefficient; (d) T significance

477 test (precipitation); (e) NDVI and temperature, precipitation multiple correlation coefficient; (f) F significance test

479 Interactive influence of multiple factors on vegetation NDVI

480 Interactive detection was utilized to evaluate the impacts of the interaction of 481 different driving factors on vegetation NDVI, which was helpful to further investigate 482 the driving mechanism of vegetation coverage change in various regions of China. 483 The results showed that the q values of the interaction among factors in most areas 484 were larger than that of single factor, indicating that the influences of driving factors 485 on vegetation NDVI were not independent, but a process of interaction and mutual 486 enhancement. In this paper, the vegetation NDVI of 1981(average status of 1981, 4871982 and 1983) and 2019 (average status of 2017, 2018, and 2019) were selected to 
explore the driving mechanisms of vegetation NDVI.

As was shown in Figure 10(a1), in northeast China in 1981, the interactive factors with higher explanation power on vegetation NDVI change were sequenced as follows: land use $\cap$ sunshine $(0.657)>$ elevation $\cap$ sunshine $(0.585)>$ soil type $\cap$ sunshine $(0.568)>$ sunshine $\cap$ temperature $(0.566)>$ aspect $\cap$ sunshine $(0.528)>$ accumulated temperature $\cap$ sunshine $(0.525)$, indicating that sunshine $\cap$ other factors acted as dominant factors. As was shown in Figure 10(a2), in 2019, the interactive factors with high explanation power were sequenced as follows: land use $\cap$ aspect $(0.473)>$ land use $\cap$ temperature $(0.446)>$ land use $\cap$ precipitation $(0.356)>$ soil type $\cap$ land use $(0.347)>$ soil type $\cap$ aspect $(0.312)>$ land use $\cap$ sunshine $(0.305)$. The explanatory power of the interaction between land use and other factors was dominant, whilst the interaction between climatic factors was relatively weak, suggesting that climate was not the main factor affecting the change of vegetation in this period. As was shown in Figure 10(b1), the maximum explanation power of interactive factors in north China in 1981 was sunshine $\cap$ temperature $(0.752)$, while that of the aspect $\cap$ slope $(0.111)$ was minimum. In addition, it could be found that the explanation power of the interaction between soil type and other factors was larger in this period. As was shown in Figure 10(b2), the land use $\cap$ precipitation had the largest explanation power of 0.770 in 2019 , whereas the aspect $\cap$ slope had the smallest explanation power of 0.149 .The interaction of precipitation, land use, soil type $\cap$ other factors had greater explanatory power in 2019. As was shown in Figure 10(c1), the soil type $\cap$ precipitation (0.669) and land use $\cap$ precipitation (0.642) in northwest China in 1981 exhibited a larger explanation power for vegetation NDVI change,. During this period, the explanatory power of the interaction between precipitation and other factors was the largest. In 2019, the explanation powers of land use $\cap$ precipitation (0.699) and land use $\cap$ sunshine (0.681) were larger, while that of the aspect $\cap$ slope was the smallest.

As was shown in Figure 10(d1) and Figure $10(\mathrm{~d} 2)$, the aspect $\cap$ precipitation 
516 (0.374) had the largest explanation power in east China in 1981, while that of 517 accumulated temperature $\cap$ temperature was the smallest with 0.074 . The explanatory 518 power of interactions between climate factors in this period was relative smaller. In 5192019 , land use $\cap$ aspect $(0.412)$ had the largest explanation power, while that of 520 accumulated temperature $\cap$ temperature $(0.073)$ was the smallest. It could be seen 521 from the figure that the explanatory power between land use $\cap$ other factors was the 522 largest. As was shown in Figure 10(e1), the interactive factors with larger explanation 523 power for vegetation NDVI change in central south China in 1981 were ranked as 524 follows: soil type $\cap$ aspect $(0.303)>$ aspect $\cap$ precipitation $(0.276)>$ soil type $\cap$ 525 sunshine $(0.268)>$ accumulated temperature $\cap$ sunshine $(0.255)>$ land use $\cap$ 526 precipitation $(0.251)>$ sunshine $\cap$ precipitation $(0.250)$. The explanatory power of 527 interaction between aspect, soil type, and precipitation was larger. As was shown in 528 Figure 10(e2), the interactive factors with larger explanation power in 2019 were 529 ranked as follows: land use $\cap$ aspect $(0.476)>$ land use $\cap$ precipitation $(0.442)>$ soil 530 type $\cap$ land use $(0.407)>$ land use $\cap$ elevation $(0.3920)>$ land use $\cap$ accumulated 531 temperature $(0.3919)>$ land use $\cap$ temperature $(0.391)$. In this period, the explanatory 532 power of the interaction between land use and other factors acted as dominant factors, 533 and the explanatory power between land use and other factors was greater than that in 534 the previous period. The interaction among climatic factors was relatively weak, 535 revealing that climate was not the main factor influencing the change of vegetation 536 NDVI in this period. As was shown in Figure 10(f1), the elevation $\cap$ sunshine $(0.810)$ 537 had the largest explanation power in southwest China in 1981, while that of aspect $\cap$ 538 slope was the smallest with 0.087. As was shown in Figure 10(f2), the elevation $\cap$ 539 sunshine had the largest explanation power of 0.807 in 2019 , while aspect $\cap$ slope had 540 the smallest value of 0.084 . For the northeast parts of China in 1981, the interactions 541 between sunshine and other factors played important roles in the change process of 542 vegetation NDVI, while land use $\cap$ other factors became the dominant factors in 543 2019. In the northwest parts, the dominant interactive factors shifted from 
544 precipitation $\cap$ other factors from land use $\cap$ other factors.

\begin{tabular}{|c|c|c|c|c|c|c|c|c|c|}
\hline Temperature & 0.124 & & & & & & & & (a1) \\
\hline Precipitation & 0431 & 0.131 & & & & & & & 0.657 \\
\hline Sunshine & 0.566 & 0.490 & 0.465 & & & & & & \\
\hline $\begin{array}{l}\text { Accumulated } \\
\text { temperature }\end{array}$ & 0287 & 0.394 & 0.525 & 0.232 & & & & & 0.056 \\
\hline Elevation & 0.429 & 0.469 & 0.585 & 0418 & 0.284 & & & & \\
\hline Slope & 0.268 & 0.190 & 0.498 & 0.331 & 0.318 & 0.098 & & & \\
\hline Aspect & 0250 & 0.217 & 0.528 & 0.360 & 0.357 & 0.186 & 0.056 & & \\
\hline Land use & 0.468 & 0.447 & 0.657 & 0.488 & 0.404 & 0349 & 0.439 & 0.286 & \\
\hline \multirow[t]{2}{*}{ Soil type } & 0.479 & 0.401 & 0.568 & 0.486 & 0457 & 0.365 & 0.490 & 0.514 & 0.326 \\
\hline & 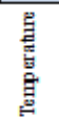 & 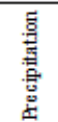 & 兽 & 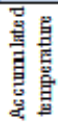 & 总 & 高 & 魷 & 鸹 & 总 \\
\hline
\end{tabular}
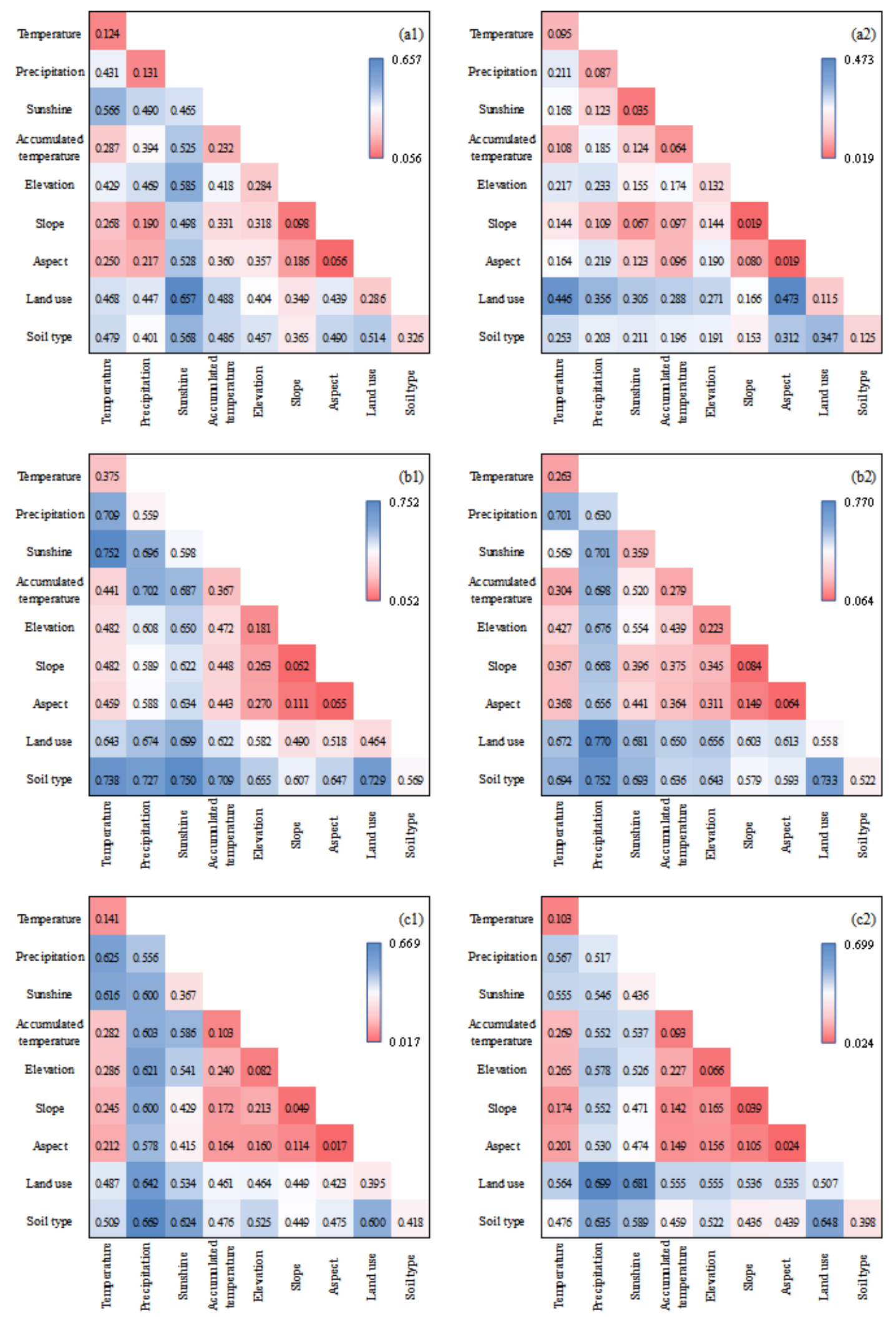

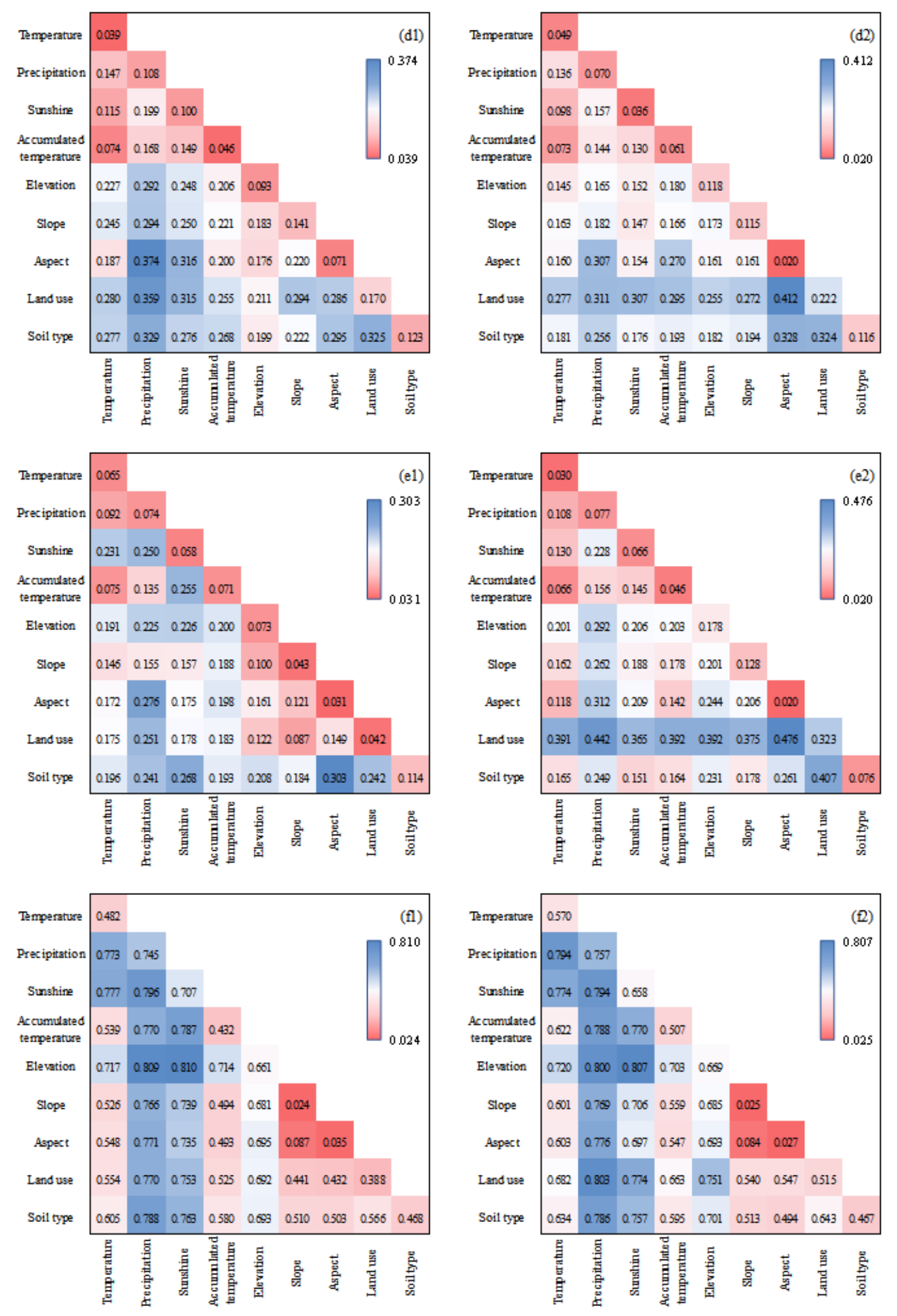

545 Figure 10. Detection of the interacting of factors affecting vegetation NDVI change in different

546 sub-regions from 1981 to 2019 (a1) northeast (1981a); (a2) northeast (2019a); (b1) north

547 (1981a) ; (b2) north (2019a) ; (c1) northwest (1981a) ; (c2) northwest (2019a); (d1) east 


\section{Discussions}

551 Comparisons of spatial-temporal change patterns of vegetation NDVI in different sub-regions

During 1981-2019, there was an increasing trend of vegetation coverage in China, especially in the middle reaches of the Yellow River basin, the middle and upper reaches of the Yangtze River basin and the Liaohe River basin. This was due to the

556 fact that during the past decades, national policies of "returning farmland to forest and 557 grassland ", "Yangtze River Ecological Protection and restoration project", "Water 558 and soil loss control project in the Yellow River Basin", and "Three-north Forest 559 Protection Project" had been implemented and remarkable ecological improvement 560 had been achieved(Gao et al.,2019; Lu et al.,2020). In addition, the vigorous 561 implementation of afforestation project in the Liaohe River basin had greatly 562 improved the regional vegetation condition. During the past 40 years, the change 563 trend of vegetation NDVI in southern Xinjiang, and western Inner Mongolia was not 564 obvious, which was consistent with the studies of Sun et al (2020). The reason was 565 that the desert and gobi were widely distributed in these above regions with scare 566 precipitation, which was not conducive to the growth and restoration of vegetation 567 (Jin et al.,2020; Ma et al.,2020).During 1981-2000, the vegetation NDVI showed a 568 slightly decreasing trend in the sub-regions of east, central, and southwest. In these 569 above zones, the rapid urbanization process, population growth rate and economic 570 development had led to the intensification of the contradiction between man and land 571 (Han et al.,2021). Although certain protection measures had been taken, the speed of 572 social and economic development far exceeded the pace of ecological and 573 environmental protection, so the change of vegetation cover was not obvious (Zhang 574 et al.,2021). After 2000, the vegetation NDVI in most sub-regions showed an 575 increasing trend, which was consistent with previous studies. During 1981-2019, the 
gravity center of vegetation NDVI moved towards the south, which indicated that the grown rate and increment in the south parts were larger than that of the north parts. Although the vegetation NDVI in most regions showed an increasing trend due to the global warming (prolong vegetation growth period, accelerate the decomposition of soil organic matter and the release of nutrient elements) and human activity (improve the agricultural management and implement vegetation construction project), the rapidly rising temperature in North China also led to varying degrees of drought, especially in the northwest parts with scare precipitation and water resource(Huo et al.,2021; Liu et al.,2021). Therefore, the grown increment of the vegetation NDVI was smaller than that of the south parts. For the sub-regions, the gravity center of the vegetation NDVI in northeast and north moved towards the south during the past 40 years because of the construction of "Three-north Forest Protection Project" and the rising temperature that were all both conductive to the grown and restoration of vegetation(Xu et al.,2021). The gravity center of the northwest showed a southward trend because that the climate in this area had been becoming warm and moist, especially in the northeast edge of Qinghai Tibet Plateau (Ning et al., 2021). In addition, the implement of "ecological environment protection project of Three-river Source Region" had also contributed to the restoration of vegetation in the southeast parts (Li et al.,2021). The gravity center of vegetation NDVI in east and central south both moved towards the south because of the implement of "Returning farmland to forest and grassland" and other ecological protection projects (Mu et al., 2020). The gravity center of vegetation NDVI showed a southwestward migration trend and it was because that under the stress of global warming, the rising temperature and increased precipitation had greatly contributed to the vegetation grown as well as the implement of "Returning grazing to grassland"(Liu et al.,2018; Jiang et al.,2020 ).

\section{Dominant factors of different sub-regions in historical periods}

Zones with positive relation between temperature and vegetation NDVI were mainly distributed in the southwest, east, and central parts of China, and the main 
604 reason was that the rising temperature could prolong the growth period of vegetation 605 and were conductive to the photosynthesis of vegetation(Sun et al.,2020). In addition, 606 the higher temperature would accelerate the decomposition of soil organic matter and 607 the release of nutrient elements, which improved the growth environment of 608 vegetation (Ma et al.,2020). The temperature had negative relations with vegetation 609 NDVI in the northwest and north parts, which was due to the fact that the rising 610 temperature would lead to severe moisture evaporation that resulted in various 611 degrees of drought (Jin et al.,2020). Zones with positive relation between precipitation 612 and vegetation NDVI were mainly located in the Inner Mongolia Plateau and the 613 middle and upper reaches of the Yellow River basin. The reason was that the 614 grasslands were widely distributed in these areas, which was more sensitive to the 615 change of soil moisture (Zhang et al., 2021). Zones with obvious positive correlation 616 between sunshine and vegetation NDVI were mainly concentrated in the junction 617 zones of Xinjiang-Gansu- Inner Mongolia and Yunnan. The reason was that sufficient 618 light was conductive to the photosynthesis of plant, especially in the alpine region 619 with lower temperature (Han et al., 2021). Zones with negative correlation with 620 sunshine were mainly were mainly located in central parts of China, and its reason 621 was that the prolonged sunshine hours would increase the surface heat, which 622 intensified the surface evapotranspiration that increased drought risk(Sun et al.,2020). 623 Zones with positive correlation of accumulated temperature were mainly located in 624 the southern, southwestern (Qianghai-Tibet plateau), and eastern China. In these 625 regions, the increasing accumulated temperature was conductive to prolong the grown 626 period of vegetation (Ma et al.,2020).

627 In the northeast parts of China in 1981, the dominant interactive factors were 628 sunshine $\cap$ others, while in 2019 , the land use $\cap$ other factors had played more 629 important role in the evolution process of vegetation system. This was because that 630 the sufficient sunshine could improve the grown environment and promote the plant 631 photosynthesis ( $\mathrm{Li}$ et al.,2021). With the implements of "Afforestation project" and 
632 urbanization, the land use $\cap$ other factors gradually became the dominant interactive

633 factors(Mu et al.,2020). In the north part of 1981, the sunshine $\cap$ temperature has the

634 largest explanatory power while the land use $\cap$ precipitation was the dominant

635 interactive factor. This was due to the fact that sunshine and temperature were both

636 conductive to plant photosynthesis, especially in zones with low temperature (Liu e

637 tal.,2018). In addition, the grassland was more sensitive to the change of temperature.

638 However, under the stress of global warming and urbanization, the precipitation and

639 human activity gradually became the dominant factors in the evolution process of

640 vegetation system(Jiang et al.,2020). In the northwest parts, the precipitation $\cap$ other

641 factors had the largest explanatory power in 1981, while the land use $\cap$ other factors

642 played more important role in the change of vegetation NDVI. This was because that

643 the water resources were one of the limiting factors for vegetation growth in arid and

644 semi-arid areas, which were mainly derived from precipitation (Gao et al.,2019). And

645 with the development of regional economic and social development, human activities,

646 such as afforestation, returning grazing to grass, and urbanization, greatly weakened

647 the influences of natural factors on the vegetation system(Sun et al.,2020). In the

648 south part, the dominant interactive factor was soil type $\cap$ aspect in 1981, while the

649 explanatory powers of land use $\cap$ other factors were larger in 2019. This was due to

650 the fact that the sufficient water and heat sources were not the restrictive factors for

651 vegetation grown, so that the soil type and terrain had played more important role in

652 the evolution process of vegetation system ( $\mathrm{Li}$ et al.,2012). In addition, the intensity

653 of human interference severer during the past 40 year, which led to drastic changes of

654 land use (Liu et al.,2015a). In the southwest part, the elevation and sunshine had the

655 largest explanatory power in both 1981 and 2019. This was because that the eco-

656 environment of these regions was characterized by high elevation and large

657 topographic relief, which greatly influenced the spatial and temporal changes of

658 vegetation NDVI (Li and Shi, 2000). 


\section{Conclusion}

Base on the datasets of GIMMS NDVI and MODIS NDVI, gravity center model and geodetector had been introduced to quantitatively analyze and discussed the spatial-temporal evolution pattern of vegetation NDVI in different sub-regions from the perspective of geographical division, and furthermore clarified the dominant driving factors of vegetation NDVI evolution in different historical periods of each sub-region. The main conclusions were as follows:

(1) The spatial distribution of vegetation NDVI in China showed a decreasing trend from the southeast to the northwest as a whole. Prior to 2000, the average vegetation NDVI in most sub-regions of China showed a decreasing trend, while there was an obvious increasing trend in all areas after 2000.

(2) Zones with obvious increasing NDVI (change rate $>30 \%$ ) were mainly distributed in the middle reaches of the Yellow River Basin, the middle and upper reaches of the Yangtze River Basin and the Liaohe River Basin. The stable zones ($10 \%<$ change rate $10 \%$ ) was the most widely distributed and mainly concentrated in the south of Xinjiang, the west of Inner Mongolia and the north of the Qinghai-Tibet Plateau.

(3) During1981-2019, the gravity center of national vegetation NDVI was mainly concentrated in Yan'an and Tongchuan in Shaanxi Province, showing a southward migration trend as a whole and which indicated that the increment and growth rate of the vegetation NDVI in southern part was greater than that of the northern part.

(4) There were significant differences in the correlation between vegetation NDVI and climatic factors in different sub-regions. The growth of vegetation in southern China was mainly affected by temperature, whereas that in the north was mainly affected by precipitation. In addition, the vegetation grown was comprehensively affected by temperature and precipitation in some zones, such as southern Xinjiang, and western Inner Mongolia. 
(5) In 1981, the sunshine $\cap$ other factors in northeast China played a dominant 688 role in the evolution process of vegetation, whilst in 2019, the explanatory power of

689 land use $\cap$ other factors were the largest .The explanation power of precipitation, 690 land use and soil types in north China was larger, whereas the explanation power of 691 land use $\cap$ other factors was larger in east China and central south China. The 692 explanatory power of precipitation $\cap$ various factors in northwest and southwest 693 China was the largest.

\section{Acknowledgments}

695 This work was supported by the technology project of State Grid Corporation of 696 China headquarters(grant no.5500-202140127A);National Natural Science 697 Foundation of China (grant no.42101306); Natural Science Foundation of Shandong 698 Province(grant no.ZR2020BD054).

\section{Competing Interests}

700 The authors have no relevant financial or non-financial interests to disclose.

\section{$701 \quad$ References}

702 Chen C, Wang YM, Li YY, Zhou S (2021) The law of vegetation change and its influencing 703 factors in different climatic regions of the Yellow River Basin from 1982 to 2015. Journal of Yangtze River Scientific Research Institute 1-9

Chen ST, Guo B, Yang F, Han BM, Fan YW, Yang X, He TL, Liu Y, Yang WN (2020) Spatial and temporal patterns of NPP and its response to climate change in the Qinghai-Tibet Plateau from 2000 to 2015. Journal of Natural Resources 35(10): 2511-2527

708 Fang JY, Piao SL, He JS (2003) Vegetation activities in China have been increasing in the past 20 years. Science in China (Series C) 2003(06): 554-565

Gao JB, Jiao KW, Wu SH (2019) Investigating the spatially heterogeneous relationships between climate factors and NDVI in China during 1982 to 2013. Science Press 29(10): 1597-1609

712 Gomes E, Inacio M, Bogdzevič K, Kalinauskas M, Karnauskaitė D, Pereira P (2021) Future land713 use changes and its impacts on terrestrial ecosystem services: A review. The Science of the total environment 781: 146716-146716 
715 Guo B, Luo W, Han BM (2019) Multiple spatial-temporal scale change patterns of rainfall 716 erosivity in China over past 58 years based on gravity centre model. Geomatics, natural 717 hazards and risk 10(1): 2200-2219

718 Guo B , Wen Y (2020) An optimal monitoring model of desertification in Naiman Banner based 719 on feature space utilizing Landsat 8 OLI Image. Journal of Engineering 8: 4761-4768

720 Guo B , Zang WQ, Luo W (2020a) Spatial-temporal shifts of ecological vulnerability of Karst 721 Mountain ecosystem-impacts of global change and anthropogenic interference. Science of the Total Environment 74: 140256

Guo B , Zang WQ, Luo W, Wen Y, Yang F, Han BM, Fan YW, Chen X, Qi Z, Wang Z, Chen ST, Yang X (2020b) Detection model of soil salinization information in the Yellow River Delta based on feature space models with typical surface parameters derived from Landsat8 OLI image. Geomatics, Natural Hazards \& Risk 11(1): 288-300

Guo B, Zang WQ, Yang F, Han BM, Chen ST, Liu Y, Yang X, He TL, Chen X, Liu CT, Gong R (2020c) Spatial and temporal change patterns of net primary productivity and its response to climate change in the Qinghai-Tibet Plateau of China from 2000 to 2015. Journal of Arid Land 12(1): 1-17

Guo B, Zang WQ, Yang X, Huang XZ, Zhang R, Wu HW, Yang LA, Wang Z, Sun GQ, Zhang Y (2020d) Improved evaluation method of the soil wind erosion intensity based on the cloudAHP model under the stress of global climate change. Sci Total Environ 746: 141271

Hu CJ, Guo L (2012) Advances in the research of ecological effects of vegetation restoration. Ecology and Environment Sciences 21(09): 1640-1646

739 Huo H, Sun CP (2021) Spatiotemporal variation and influencing factors of vegetation dynamics 740 based on Geodetector: A case study of the northwestern Yunnan Plateau, China. Ecological Indicators 130: 108005 
Jiang HL, Xu X, Guan MX, Wang LF, Huang YM, Jiang, Y (2020) Determining the contributions of climate change and human activities to vegetation dynamics in agro-pastural transitional zone of northern China from 2000 to 2015. Science of the Total Environment 718: 134871

Jin K (2019) The Spatial-temporal change of vegetation cover in China and its relationship with climate and human activities. Northwest A \& F University. Xi'an

Jin K, Wang F, Han JQ, Shi SY, Ding WB (2020) Contribution of climatic change and human activities to vegetation NDVI change over China during 1982-2015. Sciences and Natural Resources Research 75(05): 961-974

Josep P, This R, Iolanda F (2009) Phenology Feedbacks on Climate Change. Science 324(5929): $887-888$

Li JG, Yan QW, Xiong JB, Huang YY (2016) Variation of vegetation index in coal Mining Areas in Guizhou Province and its affecting factors. Journal of Ecology and Rural Environment 32(03): 374-378

Li X, Yuan JG, Meng D (2018) Spatial-temporal distribution of vegetation net primary

Li XB, Shi PJ (2000) Sensitivity analysis of variation in NDVI, temperature and precipitation in typical vegetation types across China. Acta Phytoecologica Sinica 03: 379-382

Liu HY, Jia JH, Lin ZS, Wang ZY, Gong HB (2021) Relationship between net primary production

Liu HY, Zhang MY, Lin ZS, Xu XJ (2018) Spatial heterogeneity of the relationship between vegetation dynamics and climate change and their driving forces at multiple time scales in Southwest China. Agricultural and Forest Meteorology 256-257: 10-21

Liu LL, Liu LY, Hu Y (2012) Remote sensing monitoring and analysis of the start time of Eurasian vegetation growing season from 1982 to 2006. Progress in Geography 31(11): 1433-1442 
Li SJ, Wang JM, Zhang M, Tang Q (2021) Characterizing and attributing the vegetation coverage changes in North Shanxi coal base of China from 1987 to 2020. Resources Policy 74: 102331

Liu XF, Zhu XF, Pan YZ, Li YZ, Zhao AZ (2015a) Spatiotemporal changes in vegetation coverage in China during 1982-2012. Acta Ecologica Sinica 5(16): 5331-5342

Liu Y, Yan L, Li SC, Safa M (2015b) Spatial and temporal patterns of global NDVI trends: correlations with climate and human factors. Remote Sensing 7(10): 13233-13250

Lu QQ, Jiang T, Liu DL, Liu ZY (2020) The response characteristics of NDVI with different vegetation cover types to temperature and precipitation in China. Ecology and Environment Sciences 29(01): 23-34

Ma ZC, Yu HB, Cao CM, Zhang QF, Hou LL, Liu YX (2020) Spatiotemporal Characteristics of Fractional Vegetation Coverage and Its Influencing Factors in China. Resources and Environment in the Yangtze Basin 29(06): 1310-1321

Mu SJ, Li B, Yao J, Yang GS, Wan RR, Xu XB (2020) Monitoring the spatio-temporal dynamics of the wetland vegetation in Poyang Lake by Landsat and MODIS observations. Science of the Total Environment 725: 138096

Ning K, Wang NA, Yang ZJ, Zhang LL, Wang YX, Li ZL, Bi ZW (2021) Holocene vegetation history and environmental changes inferred from pollen records of a groundwater recharge lake, Badain Jaran Desert, northwestern China. Palaeogeography, Palaeoclimatology, Palaeoecology 577: 110538

Peng KF, Jiang WG, Hou P, Sun CX, Zhao X, Xiao RL (2020) Spatiotemporal variation of vegetation coverage and its affecting factors in the Three-river-source National Park. Chinese Journal of Ecology 39(10): 3388-3396

Peng WF, Zhang DM, Luo YM, Tao S, Xu XL (2019) Influence of natural factors on vegetation NDVI using geographical detection in Sichuan Province. Acta Geographica Sinica 74(9): $1758-1776$

Piao SL, Wang XH, Ciais P (2011) Changes in satellite derived vegetation growth trend in temperate and boreal Eurasia from 1982 to 2006. Global change biology 17(10): 3228-3239 
in Anhui based on barycenter model. China Land Science 31(06): 34-41

799

800

801

802

803

804

805

806

807

808

809

810

811

812

813

814

815

816

818

819

820

Shi DD, Yang T, Hu JM (2018) Spatial-temporal variation of NDVI-based vegetation during the growing-season and its relation with climatic factors in the Yellow River Source Region. Mountain Research 36(02): 184-193

Sun YL, Qian S, Yan H, Xu LL, Wang Y, Cao Y (2019) Spatial-temporal dynamics of vegetation ecosystem in typical coal mining area of Yunnan province during 2000-2018: A case study in Lincang. Ecology and Environment Sciences 28(12): 2381-2389

Sun JK, Niu HP, Yuan M (2020) Analysis on NPP spatial pattern change of terrestrial vegetation ecosystem in China. Transactions of the Chinese Society of Agricultural Machinery 51(06): $162-168$

Wu D, Wu H, Zhao X, Zhou T, Tang BJ, Zhao WQ, Jia K (2014) Evaluation of Spatiotemporal Variations of Global Fractional Vegetation Cover Based on GIMMS NDVI Data from 1982 to 2011. Remote Sensing 6(5): 4217-4239

Wu HW, Guo B, Fan JF, Yang F, Han BM, Wei CX, Lu YF, Zang WQ, Zhen XY, Meng C (2021) A novel remote sensing ecological vulnerability index on large scale: A case study of the ChinaPakistan Economic Corridor region. Ecological Indicators 2021: 107955

Wu ZL, Jia WX, Zhao Z, Zhang YS, Liu YR, Chen JH (2015) Spatial-temporal variations of vegetation and its correlation with climatic factors in Qilian Mountains from 2000 to 2012. Arid Land Geography 38(06): 1241-1252

Xu XJ, Liu HY, Jiao FS, Gong HB, Lin ZS (2021) Nonlinear relationship of greening and shifts from greening to browning in vegetation with nature and human factors along the Silk Road Economic Belt. The Science of the total environment 766: 142553

Yang X, Guo B, Han BM, Chen ST, Yang F, Fan YW, He TL, Liu Y (2019) Analysis of the spatialtemporal evolution patterns of NPP and its driving mechanisms in the Qinghai-Tibet Plateau. Resources and Environment in the Yangtze Basin 28(12): 3038-3050

Zhang JH, Feng ZM, Jiang LG, Yang ZY (2015) Analysis of the correlation between NDVI and climate factors in the Lancang River Basin. Journal of Natural Resources 30(09): 1425-1435 Zhang M, Lin H, Long XR, Cai YT (2021) Analyzing the spatiotemporal pattern and driving 

the Total Environment 780: 146615

Zhang SY, Nie Y, Zhang HY, Li YL, Han YD, Liu XH, Wang B (2020) Spatiotemporal variation of vegetation NDVI and its driving forces in Inner Mongolia based on geodetector. Acta Agrestia Sinica 28(05): 1460-1472

831 Zhao J, Du ZQ, Wu ZT, Zhang H, Guo N, Ma ZT, Liu XJ (2018) Seasonal variations of day and nighttime warming and their effects on vegetation dynamics in China's temperate zone. Acta Geographica Sinica 73(3): 395-404 meteorological factors in Sichuan Province. Bulletin of Soil and Water Conservation 36(02): 99-104

Zhong L, Ma YM, Salama MS, Su ZB (2010) Assessment of vegetation dynamics and their response to variations in precipitation and temperature in the Tibetan Plateau. Climatic Change 103(3-4): 519-535

Zhu L, Yang AM, Xia XX, Wu HQ (2020) Spatial distribution pattern and change characteristics analysis of cultivated land in the Manas River Basin from 1975 to 2015. Chinese Journal of 843 